\title{
Tim-3 expression on PD-1+ HCV-specific human CTLs is associated with viral persistence, and its blockade restores hepatocyte-directed in vitro cytotoxicity
}

Rachel H. McMahan, ${ }^{1}$ Lucy Golden-Mason, ${ }^{1}$ Michael I. Nishimura, ${ }^{2}$ Brian J. McMahon, ${ }^{3,4}$ Michael Kemper, ${ }^{5}$ Todd M. Allen, ${ }^{5}$ David R. Gretch, ${ }^{6}$ and Hugo R. Rosen ${ }^{1,7,8}$

\begin{abstract}
1Department of Medicine, Division of Gastroenterology and Hepatology, University of Colorado Denver, Denver, Colorado, USA. ${ }^{2}$ Cancer Center, Department of Surgery, University of South Carolina, Charleston, South Carolina, USA. ${ }^{3}$ Alaska Native Tribal Health Consortium (ANTHC), Liver Disease and Hepatitis Program, Anchorage, Alaska, USA. ${ }^{4}$ Arctic Investigations Program, Division of Emerging Infections and Surveillance Services, National Center for Preparedness, Detection, and Control of Infectious Diseases, Centers for Disease Control and Prevention, Anchorage, Alaska, USA. ${ }^{5}$ Ragon Institute of MGH, MIT, and Harvard, Massachusetts General Hospital, Charlestown, Massachusetts, USA. ${ }^{6}$ Division of Laboratory Medicine, University of Washington, Seattle, Washington, USA. ${ }^{7}$ National Jewish Health, Denver, Colorado, USA. ${ }^{8}$ Denver VA Center, Denver, Colorado, USA.
\end{abstract}

\begin{abstract}
Having successfully developed mechanisms to evade immune clearance, hepatitis C virus (HCV) establishes persistent infection in approximately $75 \%-80 \%$ of patients. In these individuals, the function of $\mathrm{HCV}$-specific $\mathrm{CD8}^{+} \mathrm{T}$ cells is impaired by ligation of inhibitory receptors, the repertoire of which has expanded considerably in the past few years. We hypothesized that the coexpression of the negative regulatory receptors $\mathrm{T}$ cell immunoglobulin and mucin domain-containing molecule 3 (Tim-3) and programmed death 1 (PD-1) in HCV infection would identify patients at risk of developing viral persistence during and after acute HCV infection. The frequency of PD-1-Tim-3- $\mathrm{HCV}$-specific CTLs greatly outnumbered PD- ${ }^{+} \mathrm{Tim}^{-} 3^{+} \mathrm{CTL}$ in patients with acute resolving infection. Moreover, the population of $\mathrm{PD}-1^{+} \mathrm{Tim}-3^{+} \mathrm{T}$ cells was enriched for within the central memory $T$ cell subset and within the liver. Blockade of either PD-1 or Tim-3 enhanced in vitro proliferation of HCV-specific CTLs to a similar extent, whereas cytotoxicity against a hepatocyte cell line that expressed cognate HCV epitopes was increased exclusively by Tim-3 blockade. These results indicate that the coexpression of these inhibitory molecules tracks with defective $T$ cell responses and that anatomical differences might account for lack of immune control of persistent pathogens, which suggests their manipulation may represent a rational target for novel immunotherapeutic approaches.
\end{abstract}

\section{Introduction}

Chronic viral infections, such as those caused by HCV, HBV, and $\mathrm{HIV}$, are among the leading causes of morbidity and mortality in the world (1). These viruses have successfully developed mechanisms to evade immune clearance in the majority of infected individuals (2). A large proportion of patients fails to respond to antiviral treatment or develop significant drug toxicity (3), thus remaining at risk for disease progression. The consequences of chronic HCV infection represent compelling health problems, accounting for the most frequent cause of viral-related cirrhosis and liver cancer and the leading indication for liver transplantation in the United States (4).

Individuals who spontaneously control the acute phase of virus replication demonstrate polyfunctional $\mathrm{HCV}$-specific $\mathrm{CD}^{+}$and $\mathrm{CD}^{+} \mathrm{T}$ cells that appear critical for protective immunity. In contrast, establishment of persistent infection is characterized by lack of sufficient $\mathrm{CD}^{+} \mathrm{T}$ cell help and impaired virus-specific $\mathrm{CD}^{+}$ $\mathrm{T}$ cell responses (decreased cytokine production, proliferation, and cytotoxicity; refs. 5, 6). The failure of $\mathrm{CD}^{+} \mathrm{CTL}$ responses directed against $\mathrm{HCV}$ in chronic infection is related to multiple factors. The low fidelity of the viral polymerase contributes to the mutability of $\mathrm{HCV}$ genomes, and CTL-mediated immune selective pressure has

Conflict of interest: The authors have declared that no conflict of interest exists. Citation for this article: J Clin Invest doi:10.1172/JCI43127. been shown to drive the evolution of escape mutations favoring viral persistence (6-10). However, viral fitness costs may inhibit the development of escape mutations, thus pointing to other crucial mechanisms such as $\mathrm{T}$ cell exhaustion. $\mathrm{T}$ cell exhaustion during chronic viral infection is associated with initial normal effector differentiation followed by a progressive loss of function over time due to sustained exposure of T cells to viral antigens $(11,12)$.

The molecular signature of $\mathrm{T}$ cell exhaustion has revealed that one common phenotype is the overexpression of inhibitory receptor molecules $(11,13)$. In this regard, the inhibitory receptor programmed death 1 (PD-1), a CD28 family costimulatory/coinhibitory molecule, is highly expressed on virus-specific exhausted CTLs cells in comparison to functional memory $\mathrm{CD}^{+} \mathrm{T}$ cells and regulates CTL dysfunction (13). The recent observation that PD-1 expression is decreased on HCV-specific CTLs that recognize mutated versus intact viral epitopes (14) underscores a plausible link between the mechanisms of mutational escape and immune exhaustion.

$\mathrm{T}$ cell immunoglobulin and mucin domain-containing molecule 3 (Tim-3) is a novel membrane protein initially identified on terminally differentiated Th1 cells in mice (15), and more recently shown to be a $\mathrm{T}$ cell exhaustion marker in humans infected with HIV (16) and HCV (17). We hypothesized that the coexpression of inhibitory molecules Tim-3 and PD-1 would demarcate particularly exhausted $\mathrm{T}$ cells and determine the virologic outcome of acute HCV infection. We used detailed surface and intracellular 
Table 1

Demographic features of study group

\begin{tabular}{lcccccc} 
Parameter & Acute $\rightarrow$ resolved & Acute $\rightarrow$ chronic & $\begin{array}{c}\text { Remote } \\
\text { resolved }\end{array}$ & $\begin{array}{c}\text { Long-term } \\
\text { chronic }\end{array}$ & $\begin{array}{c}\text { Long-term } \\
\text { chronic (liver) }\end{array}$ & $\begin{array}{c}\text { Uninfected } \\
\text { control }\end{array}$ \\
$n$ & 11 & 14 & 23 & 33 & 14 & 8 \\
Age $(\mathrm{yr})^{\mathrm{A}}$ & $41(24-82)$ & $39(19-50)$ & $49(28-59)$ & $53(21-64)$ & $53(47-59)$ & $33(21-54)$ \\
Gender (\% male) & $36 \%$ & $64 \%$ & $61 \%$ & $53 \%$ & $88 \%$ & $79 \%$ \\
Genotype (\% serotype 1) & $88 \%$ & $86 \%$ & $97 \%$ C & $100 \%$ & $100 \%$ & $\mathrm{NA}$ \\
HCV RNA (IU/ml) & 42,126 & 323,466 & $\mathrm{NA}$ & 809,028 & 596,000 & $\mathrm{NA}$ \\
\hline
\end{tabular}

AValues denote median (range). BValues denote median. ${ }^{C}$ Serotype data were available for 15 patients.

phenotypic analyses as well as multifunctional assays in patients with acute infection and well-defined outcomes, as well as those with longstanding HCV infection, including intrahepatic lymphocyte sampling. We found that the level of dual Tim-3 and PD-1 expression on HCV-specific CTLs predated the development of viral persistence, providing greater prognostic information than single expression and viral level. Moreover, the population of PD- $1^{+}$ Tim $-3^{+} \mathrm{T}$ cells was also enriched for within the central memory $\mathrm{T}$ cell $\left(\mathrm{T}_{\mathrm{CM}}\right)$ subset relative to the effector memory $\mathrm{T}$ cell $\left(\mathrm{T}_{\mathrm{EM}}\right)$ population and in the hepatic relative to the peripheral compartment. Higher expression levels of these inhibitory molecules correlated with impaired Th1/Tc1 cytokine secretion and diminished cytotoxic potential. Furthermore, whereas blockade of either PD-1 or Tim-3 enhanced proliferation of HCV-specific CTLs to a similar extent, cytotoxicity was increased predominantly by Tim-3 blockade. Taken together, these data indicate that defective $\mathrm{T}$ cell response, one of the primary reasons for lack of immune control of persistent pathogens such as HCV (18), correlates with the expression of these inhibitory molecules and that their manipulation represents a potential target for novel immunotherapeutic approaches.

\section{Results}

Tim-3 is differentially upregulated on T cells early after acute HCV infection and correlates with spontaneous resolution versus persistence. We have previously shown that patients with chronic $\mathrm{HCV}$ infection have a higher frequency of Tim-3-expressing $\mathrm{CD}^{+}{ }^{+}$and $\mathrm{CD}^{+} \mathrm{T}$ cells and that Tim-3 expression correlates with a dysfunctional phenotype and reduced Th1/Tc1 cytokine production (17). However, the kinetics of Tim-3 upregulation in early infection and whether Tim-3 correlates with development of persistence versus spontaneous recovery remains undefined. In the current analysis, we performed ex vivo multicolor flow cytometry analysis in 103 subjects (Table 1): those with acute HCV who either spontaneously resolved infection (acute $\rightarrow$ resolved; $n=11$ ) or became persistently infected (acute $\rightarrow$ chronic; $n=14$ ), with sampling performed at early (baseline or 2 months) and late $(6,9$, or 12 months after enrollment) time points. Patients with HCV RNA positivity at the late time points were considered acute $\rightarrow$ chronic.

Figure 1
We also studied 23 subjects who had spontaneously resolved HCV in the remote past (remote resolved; i.e., $\geq 2$ negative HCV RNA tests by PCR at least 3 months apart), 33 treatment-naive patients who had chronic HCV for more than 10 years (long-term chronic), 8 patients who underwent liver transplantation and from whom intrahepatic lymphocytes were derived (long-term chronic [liver]), and 14 normal healthy controls.

As shown in Figure 1, the expression of Tim-3 was significantly higher in acute $\rightarrow$ chronic patients relative to uninfected control subjects on both total $\mathrm{CD}^{+}(P=0.0047)$ and $\mathrm{CD}^{+}(P=0.0002)$ $T$ cell subsets. Importantly, all the acute $\rightarrow$ resolved patients demonstrated serum HCV RNA positivity at the first time point, which indicated that the differences in Tim-3 were not simply reflective of viral levels. Patients with acute $\mathrm{HCV}$ who became viral controllers demonstrated levels of Tim-3 expression on bulk CD4 ${ }^{+} \mathrm{T}$ cells that were comparable to normal controls (Figure 1A), whereas HCV upregulated Tim-3 expression on $\mathrm{CD}^{+}$
A

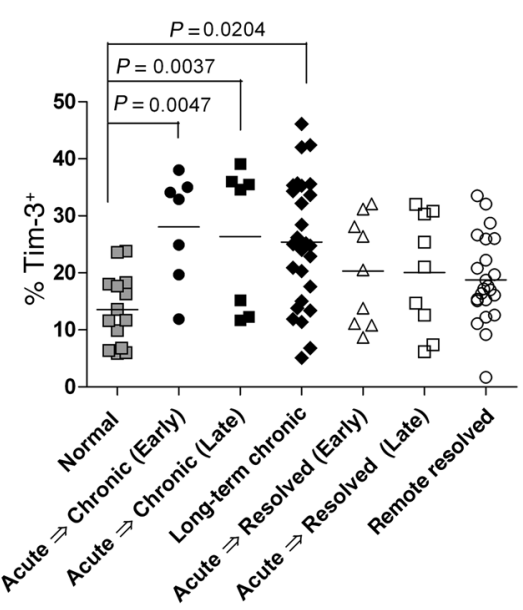

B

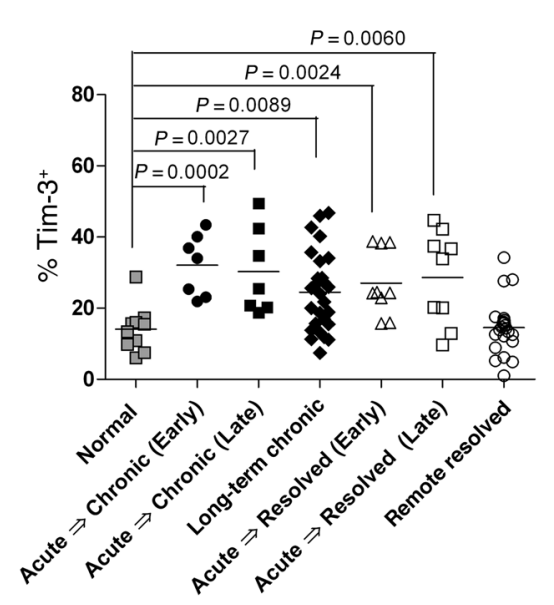

Differential Tim-3 expression on total CD4 $4^{+}$and $C D 8^{+} \mathrm{T}$ cells in acute, chronic, and resolved HCV infection. T cell populations from acutely infected patients $(n=16)$ early $(<3$ months) and late (>6 months) after infection as well as long-term chronic $(n=27)$, remotely resolved $(n=23)$, and normal control $(n=10)$ subjects were identified by staining PBMCs with antibodies against CD3, CD4, and CD8. (A and B) Percent CD4 ${ }^{+}$and CD8 ${ }^{+}$T cells expressing Tim-3. Horizontal bars denote means. (A) CD4+ $\mathrm{T}$ cells from acute $\rightarrow$ chronic patients had significantly more Tim- $3^{+} \mathrm{T}$ cells at both early and late time points after infection compared with acute $\rightarrow$ resolved patients. (B) $\mathrm{CD}^{+} \mathrm{T}$ cells from acutely infected patients had significantly higher Tim-3 levels regardless of viral outcome, but Tim-3 levels returned to normal in remote resolved patients. There was no statistical difference between acute $\rightarrow$ chronic and acute $\rightarrow$ resolved patients at comparable phases of infection. 

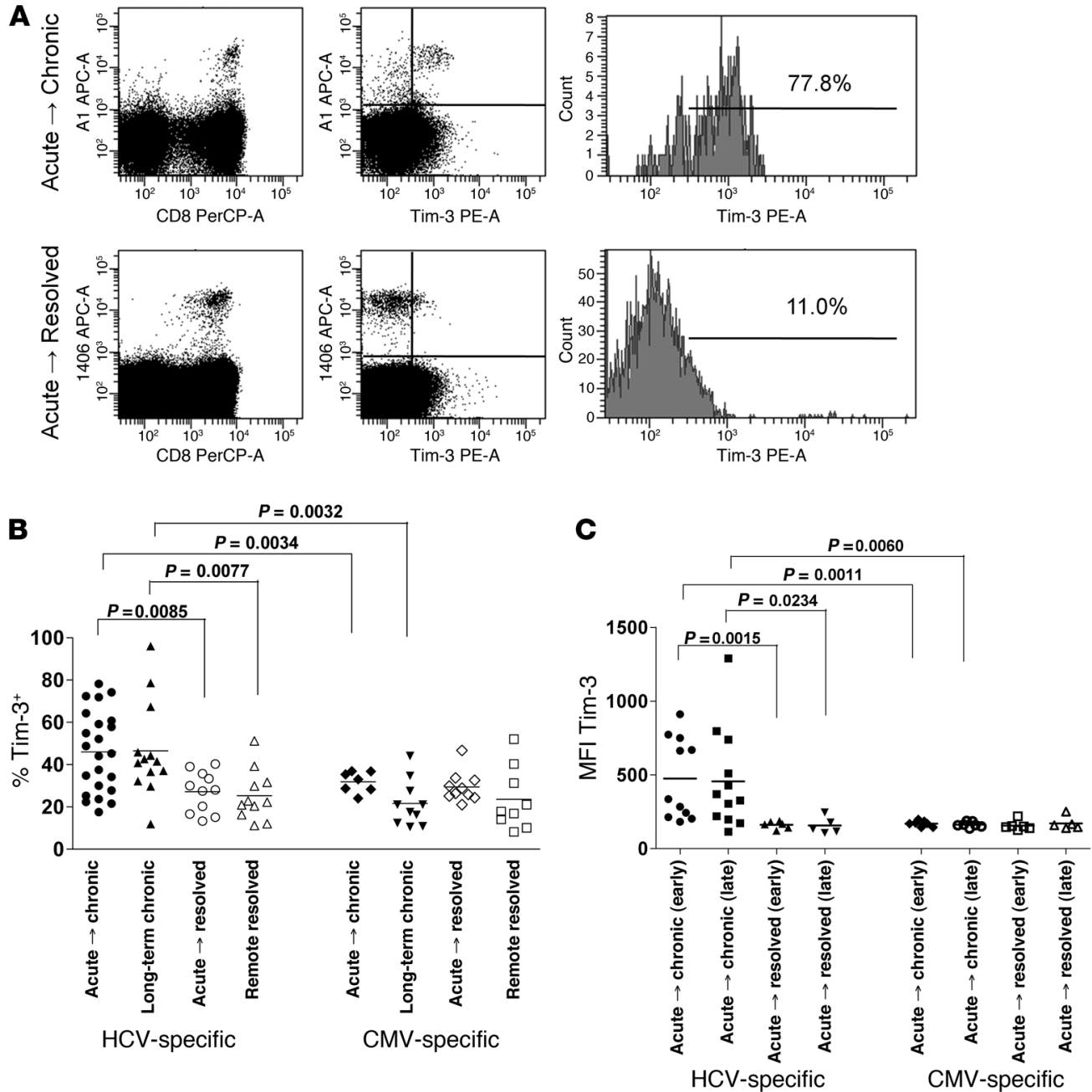

Figure 2

Tim-3 expression on HCV-specific CTLs is higher in acute $\rightarrow$ chronic patients. HCV-specific T cell populations were identified by staining with antibodies against $C D 3, C D 8$, and a panel of HCV-specific MHC class I pentamers (HLA-A2 ${ }_{1406}, \mathrm{HLA}-\mathrm{A} 2_{2594}$, and HLA-A $1_{1436}$ ) along with HLA-A2-rescricted CMV (pp65) pentamer. (A) Representative plots of Tim-3 expression on HCV-specific T cells from 1 acute $\rightarrow$ chronic and 1 acute $\rightarrow$ resolved patient. (B and C) Percent pentamer-positive cells expressing Tim-3 (B) and MFI of Tim-3 expression (C) from acute patients (34 responses from 14 patients at 2 time points), long-term chronic patients (13 responses from 11 patients), and remote resolved patients (11 responses from 11 patients). Horizontal bars denote means. Antigen-specific T cells from acute $\rightarrow$ chronic patients expressed significantly more Tim- 3 than did those of acute $\rightarrow$ resolved patients. A similar expression pattern was seen when comparing longterm chronic with remote resolved patients. Expression of Tim-3 was higher, by both percentage and MFI, on HCV-specific T cells than on CMV-specific T cells in both acute and long-term chronic patients. There was no significant difference in the number of CMV-specific T cells expressing Tim-3 according to HCV outcome.

frequencies of Tim-3 positivity in acute $\rightarrow$ chronic relative to acute $\rightarrow$ resolved patients (Figure 2), although there was some overlap. The proportion of CTLs expressing Tim-3 in acute $\rightarrow$ chronic patients was remarkably similar to that in long-term chronic patients, and acute $\rightarrow$ resolved patients demonstrated levels similar to those of remote resolved subjects (Figure 2B). MFI, which correlates directly with the number of molecules expressed on a per-cell basis, was significantly higher for Tim-3 on HCV-specific CTLs in acute $\rightarrow$ chronic relative to acute $\rightarrow$ resolved patients (Figure 2C).

Moreover, comparison of HCV- and CMV-specific CTLs within the first year of $\mathrm{HCV}$ infection revealed that $\mathrm{CMV}$ pp65-specific CTLs had statistically lower Tim-3 expression (percent positive and MFI) than HCV-specific CTLs in patients who subsequently developed HCV persistence, consistent with and expanding our prior data in patients with chronic $\mathrm{HCV}$ infection (17). The level of Tim-3 on HCV-specific CTLs in patients with spontaneous resolution was equivalent to its expression on CMV-specific CTLs, indicating that viral control results in normalization of Tim-3 expression.

Correlation between viral sequence variation and Tim-3 levels on HCV-specific T cells in acute $H C V$ infection. Recent data in acute $\mathrm{HCV}$ infection showed that PD-1 levels decreased on $\mathrm{T}$ cells specific for epitopes that have undergone substitu-

$T$ cells in the earliest stages of infection regardless of outcome. The increased Tim-3 expression on bulk $\mathrm{CD}^{+} \mathrm{T}$ cells did not normalize until late after spontaneous recovery (i.e., remote resolved; Figure 1B). These data indicate that the kinetics and expression levels of Tim-3 differ on $\mathrm{CD}^{+}$and $\mathrm{CD}^{+} \mathrm{T}$ cells in acute $\mathrm{HCV}$ infection and correlate with virologic outcome.

Tim-3 expression on HCV-and CMV-specific CTLs. Next, we examined HCV-specific CTLs using A1-restricted NS3 ${ }_{1436}$ (ATDALMTGY) and A2-restricted NS3 ${ }_{1406}$ (KLVALGINAV), NS3 ${ }_{1073}$ (CINGVCWTV) and $\mathrm{NS5}_{2594}$ (ALYDVVTKL) pentamers. At the 2 time points in acute infection, HCV-specific CTLs demonstrated significantly higher tions, whereas PD-1 levels increased or modestly decreased when the cognate epitope sequence was maintained (14). We found that acutely HCV-infected patients demonstrating consensus HCV sequences have significantly higher frequencies of Tim $-3^{+}$CTLs (Supplemental Figure 1; supplemental material available online with this article; doi:10.1172/JCI43127DS1), further supporting the hypothesis that the expression of inhibitory molecules on T cells specifically targeting nonescaped epitopes may contribute to viral persistence (14).

Dual expression of PD-1 and Tim-3 on HCV-specific CTLs defines a subset of acutely HCV-infected patients more likely to develop viral persistence and 

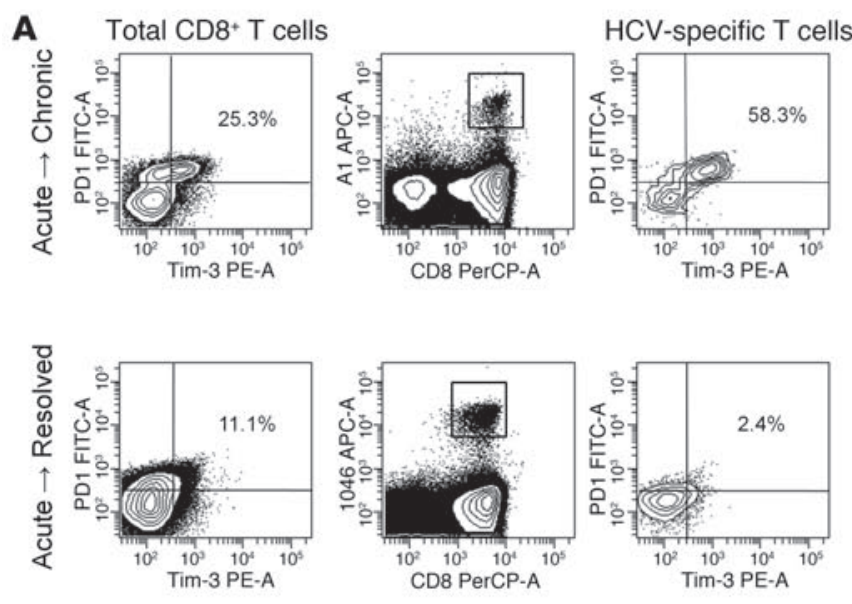

\section{C}

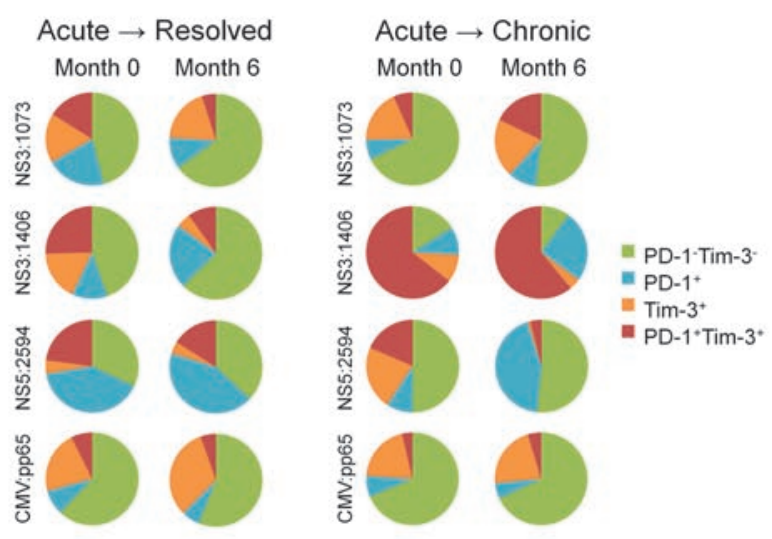

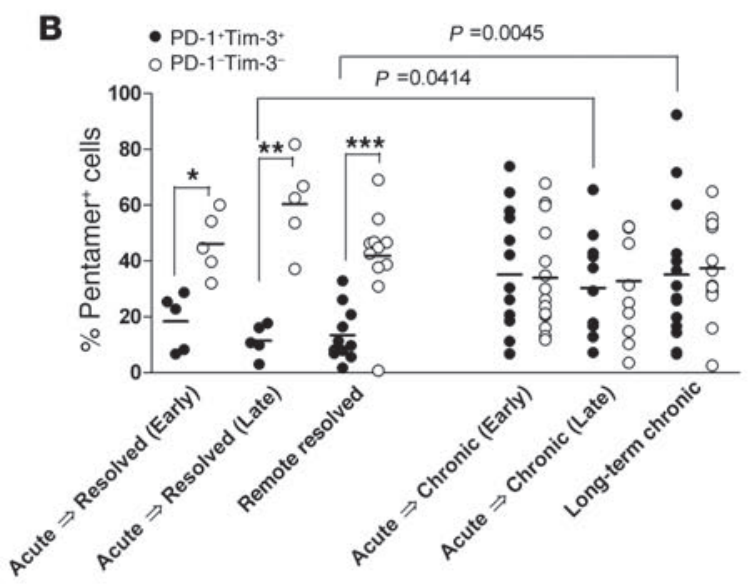

D

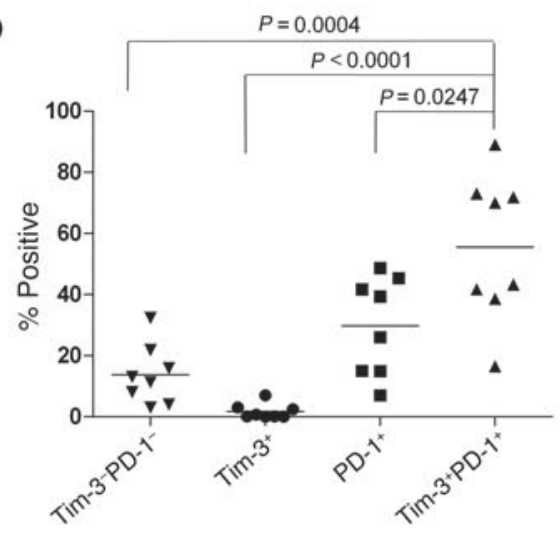

Liver

Figure 3

Dual expression of Tim-3 and PD-1 on virus-specific CTLs predicts acute development of persistence. HCV-specific T cell populations were identified by staining with antibodies against CD3, CD8, and a panel of MHC class I pentamers (HLA-A2 ${ }_{1406}, \mathrm{HLA}-\mathrm{A} 2_{2594}, \mathrm{HLA}-\mathrm{A} 2_{1073}$, and HLA$\left.A 1_{1436}\right)$. (A) Representative plots showing dual expression of PD-1 and Tim-3 on total CD8 $8^{+} \mathrm{T}$ cells and HCV-specific T cells from an acute $\rightarrow$ chronic and an acute $\rightarrow$ resolved patient. (B) Percentage PD-1+Tim-3+ or PD-1-Tim-3- pentamer-positive cells from early and late acute $\rightarrow$ chronic and acute $\rightarrow$ resolved, long-term chronic, and remote resolved patients. Antigen-specific $\mathrm{T}$ cells from acute $\rightarrow$ resolved and remote resolved patients had significantly more PD-1+Tim- $3^{+}$than PD-1-Tim- $3^{-}$cells $\left({ }^{\star} P=0.039,{ }^{\star \star} P=0.0062,{ }^{* \star \star} P=0.0009\right)$. Conversely, the frequencies of $\mathrm{PD}-1^{+}$Tim $-3^{+}$and PD-1-Tim-3- CTLs were equivalent in acute $\rightarrow$ chronic patients. (C) Boolean graphs from 2 representative acutely infected patients showing the percentage of HCV- and CMV-specific T cells that expressed Tim-3 and PD-1 at early and late time points after infection. (D) Percent intrahepatic HCV-specific CTLs expressing Tim-3, PD-1, or both. The predominant phenotype of liver-resident CTLs was PD-1+Tim-3+, and the least frequent was PD-1-Tim- $3^{+}$. Horizontal bars in $\mathbf{B}$ and $\mathbf{D}$ denote means.

represents the predominant intrabepatic phenotype in longstanding infection. In the study by Jones and colleagues profiling HIV infection, Tim-3 and PD- 1 were expressed on distinct populations of T cells, and dual expression was infrequent, indicating these inhibitory molecules mark distinct subsets of exhausted T cells in HIV infection (16). In contrast, in chronic HCV infection, the proportion of dual PD $-1^{+}$Tim $-3^{+}$cells was increased (on average, more than $30 \%$ of HCV-specific CTLs were PD- $1^{+}$Tim- $3^{+}$), as previously reported by our group (17). In the current study, we found that expression of PD-1 or Tim-3 correlated with diminished antiviral cytokine production by HCV-specific CTLs (Supplemental Figure 2). Thus, we hypothesized that PD-1 $1^{+}$Tim- $3^{+}$CTLs would accumulate early in infection in acute $\rightarrow$ chronic patients and that long-term chronic patients would display higher frequencies than remote resolved subjects (Figure 3A). At all time points studied, patients who resolved HCV infection demonstrated lower frequencies of
PD-1 ${ }^{+}$Tim-3 $3^{+}$than PD-1-Tim-3- HCV-specific CTLs (acute $\rightarrow$ resolved early, $P=0.039$; acute $\rightarrow$ resolved late, $P=0.0062$; remote resolved, $P=0.0009$; Figure $3 \mathrm{~B})$. In contrast, in patients who developed viral persistence, the frequency of these 2 populations was equivalent from the earliest stages of infection to the long-term phase. Moreover, the relative proportions of $\mathrm{PD}-1^{+} \mathrm{Tim}-3^{+}$versus PD-1-Tim-3- CTLs were statistically different between late time points in acute infection $(P=0.0414)$ and remote resolved or longterm chronic infection $(P=0.0045)$. Figure $3 \mathrm{C}$ shows the expression of PD-1 and Tim-3 on CTLs specific for HCV or CMV epitopes in 2 representative patients at early and late time points in acute $\mathrm{HCV}$ infection. There was a consistent decrease in the frequency of $\mathrm{PD}-1^{+}$Tim- $3^{+} \mathrm{HCV}$-specific CTLs over time in the acute $\rightarrow$ resolved patient, and a corresponding expansion of PD-1-Tim-3- CTLs. In contrast, the frequencies of PD-1- Tim- $3^{-}$cells either contracted or remained unchanged in the acute $\rightarrow$ chronic patient. Interestingly, 
A

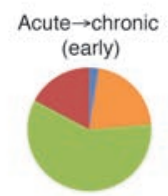

Acute $\rightarrow$ resolved (early)
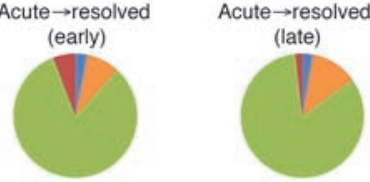

Long-term

chronic (liver)

Long-term chronic
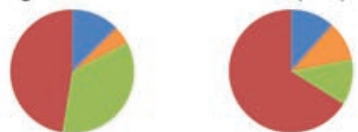

Remote resolved

- PD- $1^{\text {hi }}$ Tim- $3^{\text {lo }}$

- PD- $1^{\text {lo }}$ Tim- $3^{\text {hi }}$

- $\mathrm{PD}-1^{10} \mathrm{Tim}-3^{10}$

- PD- $1^{\text {hi Tim }}-3^{\text {hi }}$

B

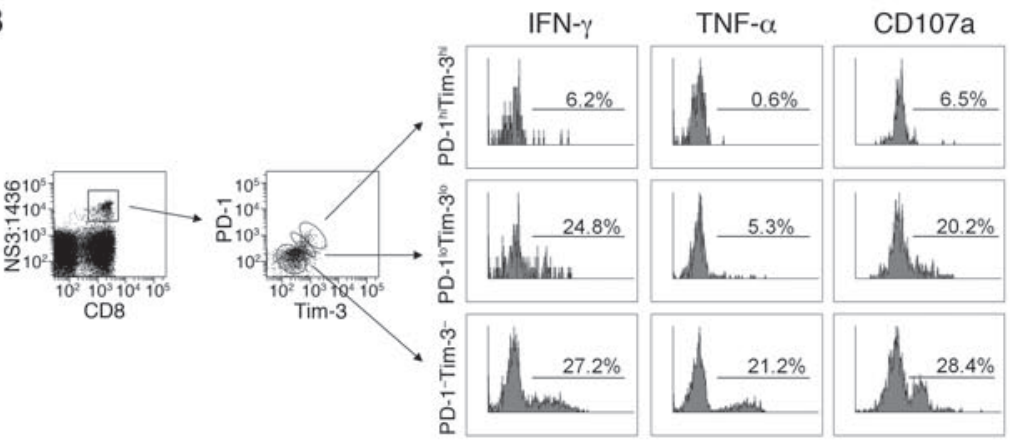

C

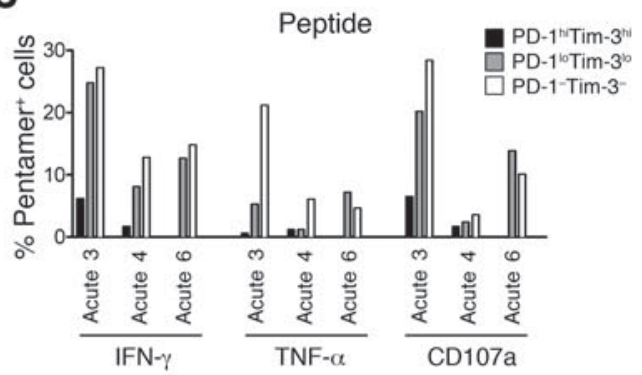

PMA/ionomycin

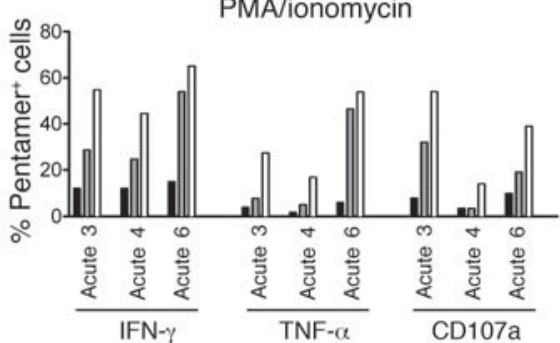

Figure 4

PD- $1^{\text {hiTim- }} 3^{\text {hi }}$ CTLs are associated with diminished antiviral cytokine production and chronic infection. (A) PD-1 ${ }^{\text {hiTim- }} 3^{\text {lo }}$, PD- $1^{\text {lo }}$ Tim- $3^{\text {hi }}$, PD-1 ${ }^{10}$ Tim- $3^{\text {lo }}$, and PD- $1^{\text {hiTim- }} 3^{\text {hi }}$ pentamer-positive $\mathrm{T}$ cells from acute $\rightarrow$ chronic, acute $\rightarrow$ resolved, long-term chronic, and remote resolved patients as well as intrahepatic T cells from long-term chronic (liver) patients. The differences between long-term chronic and remote resolved patients were highly statistically significant (see Results). (B and C) PBMCs from acute $\rightarrow$ chronic patients were stimulated with the HLA-A1restricted NS3 ${ }_{1436}$ epitope or PMA and ionomycin for 5 hours in the presence of the CD107a antibody. Cell surface staining for CD3, CD8, HLA$\mathrm{A} 1_{1436}$ pentamer, Tim-3, and PD-1 was carried out, followed by intracellular cytokine staining for IFN- $\gamma$ and TNF- $\alpha$. Flow cytometric analysis was used to determine the proportions of the PD-1 ${ }^{\text {hiTim- }} 3^{\text {hi }}$, PD- $1^{10}$ Tim- $3^{\text {lo }}$, and PD-1-Tim-3- cells producing IFN- $\gamma$, TNF- $\alpha$, and CD107a after stimulation. (B) Histograms from a representative patient with high pentamer frequency $(2.2 \%)$. (C) Percent cells producing IFN- $\gamma$, TNF- $\alpha$, and CD107a according to PD-1 and Tim-3 expression following stimulation with the NS3 ${ }_{1436}$ peptide or PMA and ionomycin. Pentamer frequencies for patients acute 4 and acute 6 are shown in Supplemental Figure 3.

this patient demonstrated viral sequence variation relative to the consensus sequence in the $\mathrm{NS}_{2594}$ epitope (variant, ALYDLVSKL; consensus, ALYDVVSKL), and CTLs targeting this epitope had a temporal decrease in $\mathrm{PD}-1^{+} \mathrm{Tim}-3^{+} \mathrm{CTL}$. The relative distribution of CMV responses remained stable over time. These data and those shown in Supplemental Figure 1 support the hypothesis that $T$ cells specifically targeting variant epitopes may downregulate the expression of inhibitory receptors, underscoring a plausible mechanistic link between mutational escape and immune exhaustion.

In prior studies of $\mathrm{HCV}$-infected patients, the liver has been shown to accumulate high levels of apoptotic, activated T cells relative to the peripheral blood (19). Therefore, we isolated intrahepatic lymphocytes from long-term chronic (liver) patients undergoing liver transplantation, thus obviating the need for in vitro expansion. We found that the majority of intrahepatic HCV-specific CTLs were PD- $1^{+}$Tim- $3^{+}$and that expression of Tim- 3 without PD-1 was relatively rare $(P<0.0001$, Figure 3D). Moreover, in patients with matched liver-derived and peripheral samples, HCVspecific CTLs within the liver demonstrated higher levels of dual PD-1 and Tim-3 expression (Supplemental Figure 3).

Relative Tim-3 and PD-1 expression correlates with the multifunctionality of HCV-specific CTLs and virologic outcome of HCV infection. We hypothesized that the gradient of $\mathrm{T}$ cell effector function and exhaustion
(20) would correlate with the extent to which CTLs expressed Tim-3 and PD-1. Recent work suggests that only a subset of exhausted viral-specific CTLs can be rescued by blockade of PD-1 and/or PD-1 ligand (PD-L) in vivo (21). While those expressing low or intermediate levels of PD-1 can be restored (21), the nonresponsive CTLs express the highest levels of PD-1 (i.e., PD-1 ${ }^{\text {hi }}$ ). Therefore, we determined whether the relative expression of PD-1 or Tim-3 was associated with outcome of viral infection with hepatitis $\mathrm{C}$, using the Boolean gate platform to create an array of possible combinations, as described previously (22). Within the $\mathrm{PD}-1^{+} \mathrm{Tim}-3^{+}$populations, we gated on 4 quadrants, yielding the following combinations: PD- $1^{\text {hi }}$ Tim- $3^{\text {hi }}$, PD- $1^{\text {lo }}$ Tim- $3^{\text {hi }}$, PD- $1^{\text {hi }}$ Tim- $3^{\text {lo }}$, and PD- $1^{\text {lo }}$ Tim- $3^{\text {lo }}$. Figure $4 \mathrm{~A}$ shows that patients with viral persistence demonstrated significantly higher frequency of the most dysfunctional HCV-specific CTLs, with PD- $1^{\text {hi }}$ Tim- $3^{\text {hi }}$ cells representing a mean of $47 \%$ in long-term chronic versus $4 \%$ in remote resolved patients ( $P=0.009$, Mann-Whitney test). On the other hand, the frequency of more functional CTLs (PD- $1^{\mathrm{lo}}$ Tim- $3^{\mathrm{lo}}$ ) was twice as high in remote resolved versus long-term chronic patients ( $71 \%$ versus $35 \%$; $P=0.01$, Mann-Whitney test). Differences were evident early in the course of infection.

Next, we evaluated whether dual PD-1 and Tim-3 expression correlated with $\mathrm{T}$ cell function. In acutely $\mathrm{HCV}$-infected patients 
A

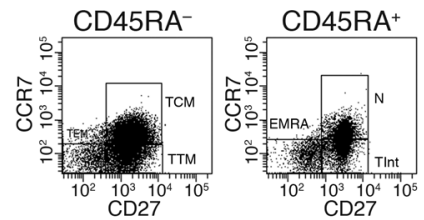

$\mathrm{CD}^{+}$

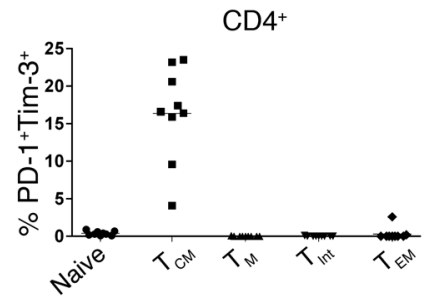

$\mathrm{CD}^{+}$

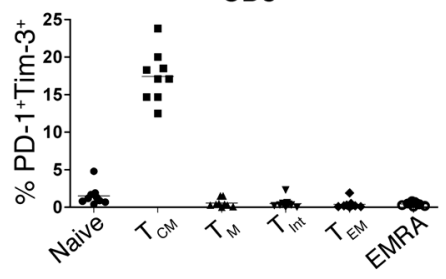

B
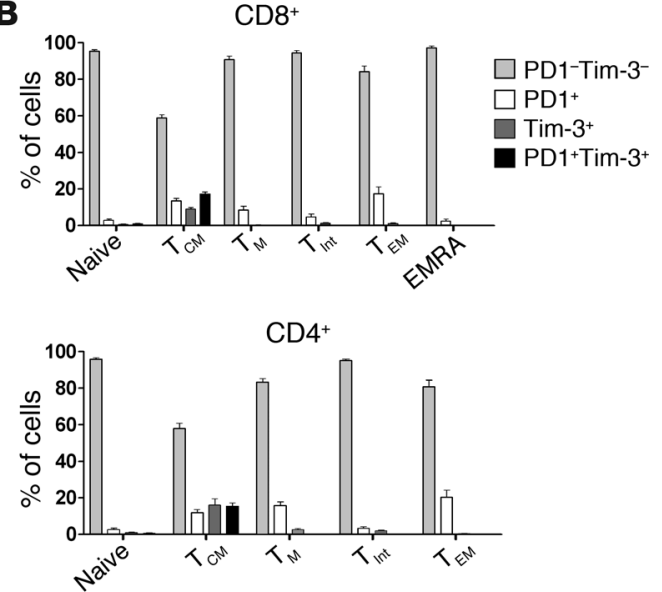

C
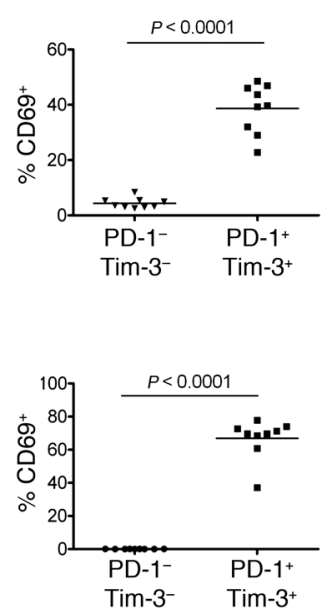

$\mathrm{CD}^{+} \mathrm{T}$ cells
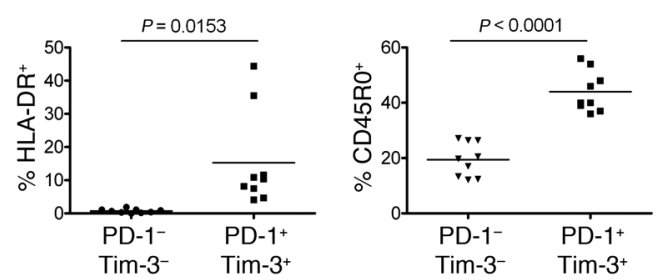

$\mathrm{CD4}^{+} \mathrm{T}$ cells
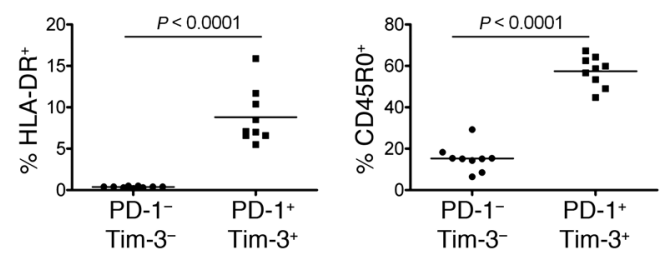

Figure 5

T cells coexpressing Tim-3 and PD-1 display a $\mathrm{T}_{\mathrm{CM}}$ phenotype. (A and B) CD4+ and CD8 ${ }^{+}$T cells from acutely infected patients $(n=9)$ were stained with antibodies against CD45RA, CCR7, and CD27 to determine differentiation phenotype (see Results). (A) Percent PD-1+Tim- $3^{+}$cells within each population. Cells expressing both PD-1 and Tim-3 were predominantly of the $T_{\text {CM }}$ phenotype. (B) Percent $\left( \pm\right.$ SEM) PD-1-Tim-3-, PD-1 ${ }^{+}$ Tim-3-, PD-1-Tim- $3^{+}$, and PD-1+Tim- $3^{+}$cells within each population. There were no significant differences in the phenotype of PD-1+Tim- $3^{+}$ T cells from normal subjects and HCV patients (not shown). (C) CD4+ and CD8 ${ }^{+}$T cells were stained with antibodies against PD-1, Tim-3, CD69, HLA-DR, and CD45RO, and the PD-1+Tim- $3^{+}$and PD-1-Tim-3- phenotypes were compared. Horizontal bars denote means. A significant portion of PD-1+Tim- $3^{+} T$ cells expressed all 3 activation/memory markers.

with high frequencies of HCV-specific T cells (Figure 4B and Supplemental Figure 4), we determined the production of antiviral cytokines and CD107a expression following short-term stimulation with cognate peptide or PMA according to the relative expression of Tim-3 and PD-1. CD107a is a lysosome-associated membrane glycoprotein expressed on the cell surface following release of the cytotoxic granule contents (23), and thus, its ex vivo expression correlates with the degranulation capacity of virus-specific CTLs. Antiviral cytokines (IFN- $\gamma$ and TNF- $\alpha$ ) and CD107a were produced to a much lesser extent within the PD- $1^{\text {hi }}$ Tim- $3^{\text {hi }}$ subset of pentamer-positive CTLs compared with PD- $1^{\mathrm{lo}} \mathrm{Tim}-3^{\mathrm{lo}}$ and PD-1Tim-3- cells (Figure 4, B and C).

It has been suggested that anatomical differences in viral replication could provide survival niches for subsets of exhausted CTLs with different properties (24). We found that the relative frequency of PD- $1^{\text {hi }}$ Tim- $3^{\text {hi }} \mathrm{HCV}$-specific CTLs was highest within the livers of patients with chronic HCV infection (Figure 3D; $P<0.0001$ ver- sus peripheral blood CTLs in patients with chronic $\mathrm{HCV}$, ANOVA). These data demonstrate that the extent to which Tim-3 and PD-1 are dually expressed on HCV-specific CTLs correlates with differential functionality, spontaneous eradication versus persistence of viral infection, and the tissue microenvironment.

$P D-1^{+} T i m-3^{+} T$ cells found within the $T_{C M} /$ noneffector subset in acute $H C V$ infection. We determined whether the composition of naive and memory $\mathrm{T}$ cell pools varied with regard to Tim-3 and PD-1 expression in acute $\mathrm{HCV}$ infection and normal controls. By convention, $\mathrm{T}$ cell subpopulations were defined on the basis of differential expression of CD45RA, CD27, and CCR7 (25). T cells were considered naive if they coexpressed CD45RA, CD27 and CCR7; 5 distinct memory $\mathrm{T}$ cell populations were classified as $\mathrm{T}_{\mathrm{CM}}\left(\mathrm{CD} 45 \mathrm{RA}^{-}\right.$

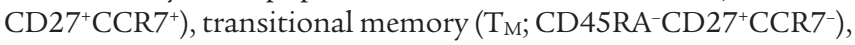
intermediate memory ( $\left.\mathrm{T}_{\mathrm{Int}} ; \mathrm{CD} 45 \mathrm{RA}^{+} \mathrm{CD} 27^{\mathrm{dim}} \mathrm{CCR} 7^{-}\right), \mathrm{T}_{\mathrm{EM}}$ (CD45RA-CD27-CR7-), and RA ${ }^{+} \mathrm{T}_{\mathrm{EM}}$ (EMRA, also known as terminally differentiated; CD45RA ${ }^{+} \mathrm{CD} 27^{-} \mathrm{CCR}^{-}$) cells (Figure 5A). 
A

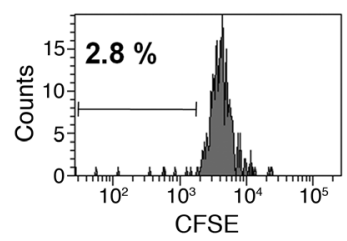

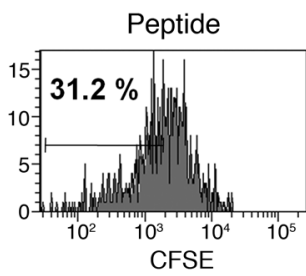

Anti-PD-L

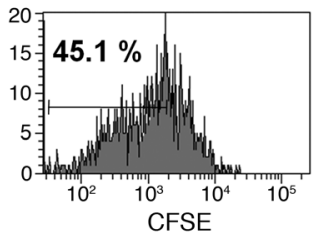

Anti-Tim-3

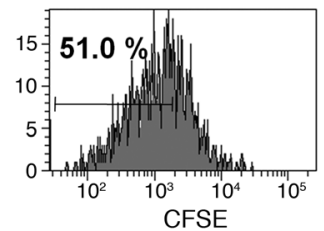

Anti-PD-L Anti-Tim-3
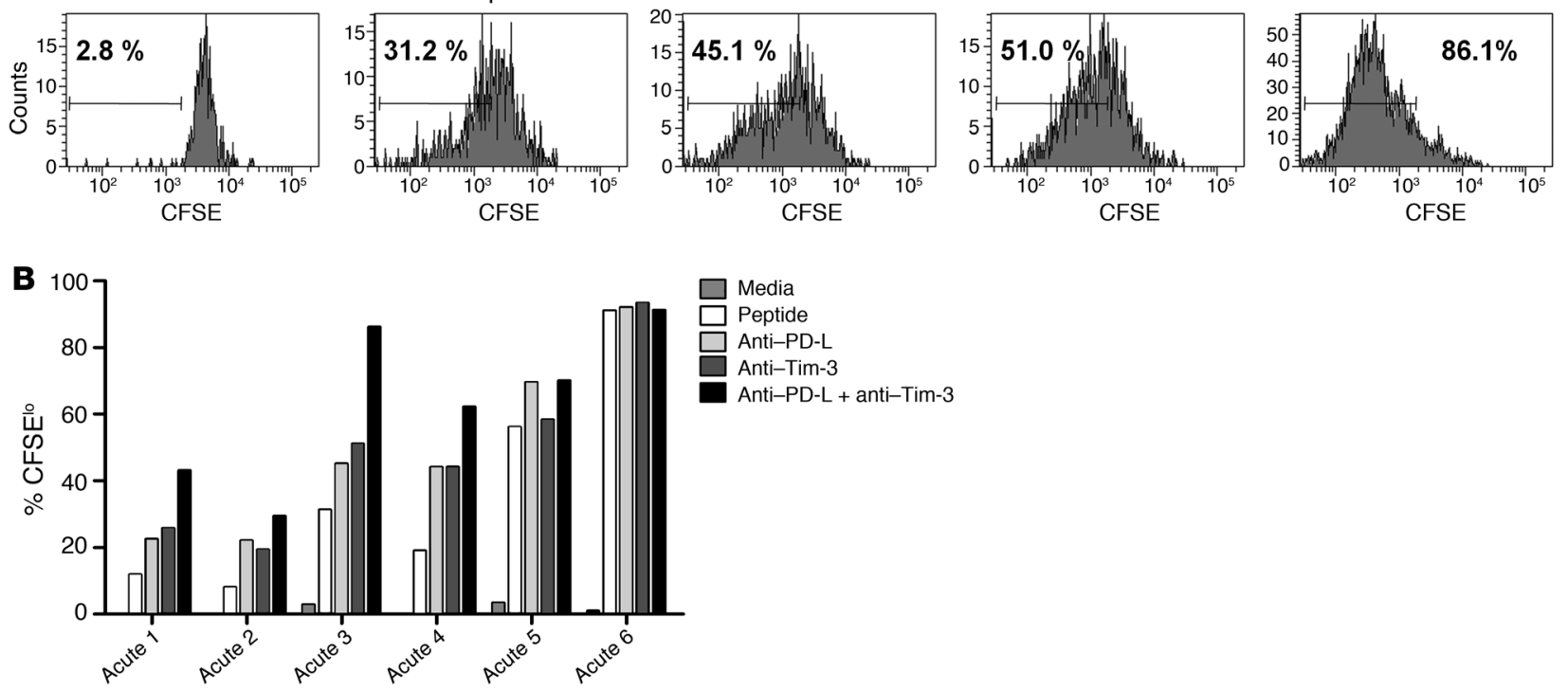

Figure 6

Blocking Tim-3 and PD-1 enhances T cell proliferation. PBMCs from 5 acute $\rightarrow$ chronic patients (acute 2-acute 6) and 1 acute $\rightarrow$ resolved patient (acute 1; ref. 8) were stained with CFSE and stimulated for 7 days with HLA-A2-restricted NS3 ${ }_{1406}$ or HLA-A1-restricted NS3 ${ }_{1436}$ peptide, IL-2 (0.5 ng/ml), anti-Tim-3 antibody (10 $\mu \mathrm{g} / \mathrm{ml})$, anti-PD-L1/PD-L2 antibodies $(10 \mu \mathrm{g} / \mathrm{ml})$, or both anti-Tim-3 and anti-PD-L1/PD-L2. HCV-specific T cells were identified by staining with anti-CD8 and HLA-A2 ${ }_{1406}$ or HLA-A $1_{1436}$ pentamers and analyzed by flow cytometry for proliferation, as measured by CFSE ${ }^{\text {lo }}$ cells. (A) Representative histograms from 1 patient showing an increase in CFSE ${ }^{\circ} \mathrm{T}$ cells after dual blocking of Tim-3 and PD-1. Percent HCV-specific T cells that proliferated are shown. (B) Percent CFSE cells from 6 patients following treatment with the indicated blocking antibodies. Blocking with either PD-1 or Tim-3 alone improved proliferation in 4 of the 6 patients, and dual blocking further enhanced proliferation.

These subsets have previously been shown to demonstrate various effector and homing functions (25-27).

We plotted the percentage of PD- $1^{+}$Tim $-3^{+}$cells within each subset and found that these cells were concentrated within the $\mathrm{T}_{\mathrm{CM}}$ cell subset (Figure $5 \mathrm{~A}$ ). Within the naive, $\mathrm{T}_{\mathrm{M}}, \mathrm{T}_{\mathrm{Int}}, \mathrm{T}_{\mathrm{EM}}$, and EMRA subsets, the vast majority of the population lacked expression of either Tim-3 or PD-1 (Figure 5B). However, within the $\mathrm{T}_{\mathrm{CM}}$ subset of both $\mathrm{CD}^{+}$and $\mathrm{CD}^{+} \mathrm{T}$ cells, a higher proportion demonstrated dual or single expression of PD- 1 and Tim-3. For CD $4^{+} \mathrm{T}$ cells, $43.2 \% \pm 3.1 \%$ expressed either single or dual Tim- 3 and $\mathrm{PD}-1$ within the $\mathrm{T}_{\mathrm{CM}}$ compartment versus $21.2 \% \pm 3.7 \%$ in the $\mathrm{T}_{\mathrm{EM}}$ compartment $(P=0.0007)$ and $4.5 \% \pm 0.6 \%$ in the naive compartment $(P<0.0001)$. For $\mathrm{CD}^{+}$ $\mathrm{T}$ cells, $40.2 \% \pm 1.7 \%$ expressed either single or dual Tim-3 and $\mathrm{PD}-1$ within the $\mathrm{T}_{\mathrm{CM}}$ compartment versus $4.8 \% \pm 0.6 \%$ in the naive compartment $(P<0.0001), 19.0 \% \pm 3.4 \%$ in the $\mathrm{T}_{\mathrm{EM}}$ compartment $(P=0.0003)$, and $2.7 \% \pm 0.9 \%$ in the EMRA population $(P<0.0001)$.

Further phenotypic profiling demonstrated that PD- $1^{+}$Tim $-3^{+}$ $\mathrm{CD}^{+}$and $\mathrm{CD}^{+} \mathrm{T}$ cells expressed higher levels of activation (CD69 and HLA-DR) and memory markers (CD45RO) than did PD-1 Tim-3- $3^{-}$cells (Figure 5C). A similar pattern was observed with $\mathrm{HCV}$-specific pentamer-binding CTLs: $\mathrm{PD}-1^{+}$Tim- $3^{+}$expression identified activated memory cells (Supplemental Figure 5A). In keeping with recent findings in a murine model of lymphocytic choriomeningitis (LCMV; ref. 28), we found that PD- $1^{+}$Tim- $3^{+}$ $\mathrm{CD}^{+} \mathrm{T}$ cells had lower levels of CD127 (Supplemental Figure 5, B and $C$, and data not shown). Differentiation of T cells into effector cells during primary immune responses has important consequences for the development of protective immunity, and taken together, our results indicate that PD- 1 and Tim- 3 coexpression demarcates a $\mathrm{T}_{\mathrm{CM}}$ phenotypic signature with limited functional capacities (29) that favor establishment of persistence.

Tim-3 blockade restores proliferation, cytotoxicity, and killing of $\mathrm{HCV}$ expressing hepatocytes. As noted previously, the development of chronic HCV infection is manifested by CTLs that are functionally impaired, displaying decreased proliferative capacity and cytotoxicity $(30,31)$. We explored the effect of single or dual PD-1 and Tim-3 blockade on proliferation and cytotoxic activity of HCV-specific CTLs. Whole PBMCs from patients with acute $\mathrm{HCV}$ were stimulated with peptide alone, peptide plus anti-Tim-3 blocking antibody, peptide plus anti-PD-L1/PD-L2 blocking antibodies, or peptide plus blocking antibodies to both PD-1 and Tim-3. Figure 6 shows that Tim-3 blockade enhanced proliferation as assessed by CFSE-based fluorescence-activated cell sorting (FACS) analysis, usually at levels comparable to anti-PD-L blockade, and had a combined additive effect in 4 of 6 patients. Remarkably, in some patients (e.g., acute 3), dual blockade yielded HCV-specific CTL proliferation in excess of 50\% over peptide stimulation alone ( $86 \%$ versus $31 \%$ ), whereas in other cases (e.g., acute 6), peptide stimulation alone resulted in high levels of proliferation that were not significantly enhanced by PD-1 and Tim-3 blockade. Interestingly, patient acute 6 demonstrated relatively lower levels of inhibitory molecule expression prior to stimulation (Table 2). Tim-3 blockade, both alone and in combination with PD-1/PD-L blockade, enhanced IFN- $\gamma$ and TNF- $\alpha$ production in supernatants by PBMCs after 48 hours (data not shown), further expanding our prior results (17). 
Table 2

Percent CTLs expressing inhibitory receptors ex vivo

\begin{tabular}{lccc}
\hline & & & \\
Patient & PD-1+ & Tim-3+ & PD-1+Tim-3+ \\
Acute 1 & $5.3 \%$ & $24.6 \%$ & $61.8 \%$ \\
Acute 2 & $9.7 \%$ & $9.7 \%$ & $64.5 \%$ \\
Acute 3 & $10.9 \%$ & $24.1 \%$ & $34.5 \%$ \\
Acute 4 & $13.2 \%$ & $27.6 \%$ & $7.2 \%$ \\
Acute 5 & $5.1 \%$ & $26.8 \%$ & $47.3 \%$ \\
Acute 6 & $3.9 \%$ & $9.2 \%$ & $5.1 \%$ \\
\hline
\end{tabular}

The cytotoxic potential of HCV-specific CTLs was gauged by 3 approaches: expression of CD107a, killing of HepG2 cells transfected with a minigene to express HCV NS3 sequences, and secretion of aspartate aminotransferase (AST) in the supernatants of CTL-hepatocyte cultures. The majority of intrahepatic HCV-specific CTLs were PD $-1^{+}$Tim $-3^{+}$, followed by PD $-1^{+}$Tim $-3^{-}$and, least frequently, PD-1-Tim- $3^{+}$(Figure 3D). We found that coculture with anti-Tim-3 enhanced CD107a upregulation more consistently than did anti-PD-L1/PD-L2 in both peripheral and intrahepatic CTLs (Figure 7). In 6 of the 7 patients shown, anti-PD-L blockade increased CD107a expression by less than $10 \%$.

Furthermore, we explored whether HCV-specific CTLs rescued by dual blockade were able to recognize endogenously processed antigen and kill a relevant target. To this end, we constructed retroviral vectors containing a minigene encoding the $\mathrm{NS}_{1406}$ (KLVALGINAV) peptide (32), then transduced HepG2 cells that naturally express HLA-A2. For the VITAL killing assay (33), target HepG2 cells expressing the $\mathrm{NS}_{1406}$ minigene or nontransduced HepG2 cells were labeled with the membrane dyes DiD and DiI (Figure 8A). The labeled target cells were then incubated with magnetic beadisolated $\mathrm{CD}^{+} \mathrm{T}$ cells after 5 days of stimulation with the $\mathrm{NS}_{1406}$ peptide in the presence or absence of the indicated blocking antibodies (Figure 8B). HCV NS3 ${ }_{1406}$-specific T cells were added at effector/target ratios based on the levels of staining with the HCV $\mathrm{NS}_{1406}$ pentamer. Antigen-specific lysis was enhanced in the presence of Tim-3 blocking antibody in all patients. AST was measured in the supernatants of CTL-hepatocyte cultures, and the higher AST levels in the presence of Tim-3 blockade (Figure 8C) mirrored the cytolysis results. In the absence of any blockade, secreted AST levels were less than $10 \mathrm{U} / 1$. Thus, using complementary approaches, we found that Tim-3 enhanced killing of HepG2 cells that expressed cognate peptide, whereas PD-L1/PD-L2 blockade had no effect. Taken together, these data indicate differential roles for PD-1 and Tim-3 signaling in mediating CTL effector functions.

\section{Discussion}

HCV infection is a highly significant clinical problem, representing one of the most frequent causes of liver failure worldwide. The experimental evidence implicating $\mathrm{CD}^{+} \mathrm{T}$ cells as pivotal in host
A
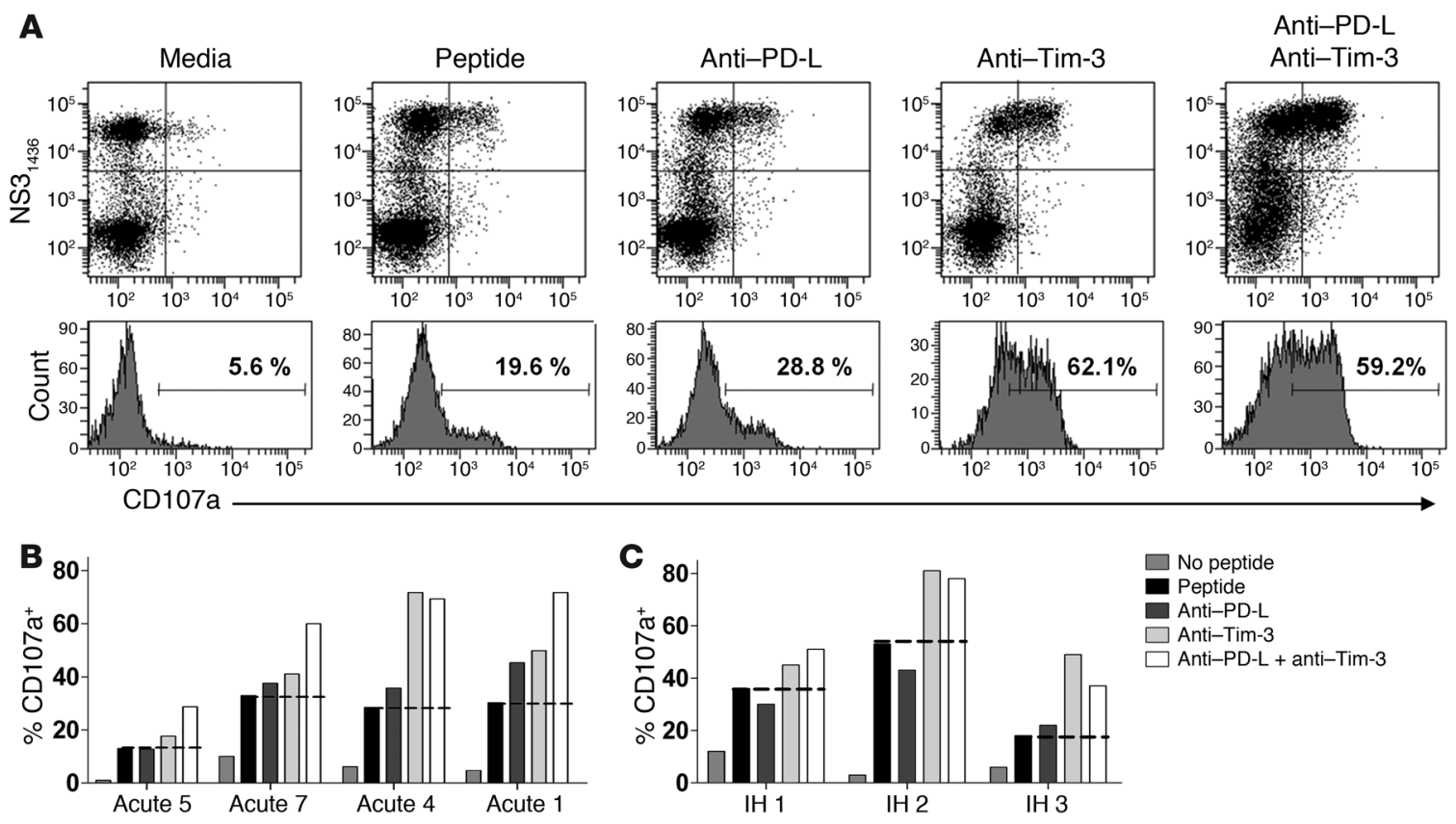

Figure 7

Dual blocking of PD-1 and Tim-3 enhances CD107a expression by HCV-specific T cells. PBMCs from patients acute 1, acute 4, acute 5, and acute 7 or intrahepatic lymphocytes from long-term chronic (liver) patients (IH 1-IH 3) were stimulated for 7 days with NS3 ${ }_{1406}$ or NS3 ${ }_{1436}$ peptide $(10 \mu \mathrm{g} / \mathrm{ml})$, IL-2 (0.5 ng/ml), and control IgG, anti-Tim-3, anti-PD-L1/PD-L2, or both anti-Tim-3 and anti-PD-L1/PD-L2 antibodies. Cells were restimulated with peptide, and CD107a antibody and brefeldin A were added to the cultures 5 hours prior to staining with anti-CD8 and HLA$\mathrm{A} 2_{1406}$ or HLA-A $1_{1436}$ pentamers. CD107a expression on HCV-specific CTLs was determined by flow cytometric analysis. (A) Representative histograms from 1 acute patient showing an increase in CD107a+ CTLs after dual blocking of Tim-3 and PD-1. (B and C) Percent HCV-specific $T$ cells expressing CD107a from (B) acute $\rightarrow$ chronic patients or $(\mathbf{C})$ intrahepatic lymphocytes from long-term chronic (liver) patients. Blocking Tim-3 alone or Tim-3 and PD-1 increased CTL cytotoxicity in both PBMCs and intrahepatic lymphocytes. Dotted lines represent CD107a expression after stimulation with peptide alone. 
A

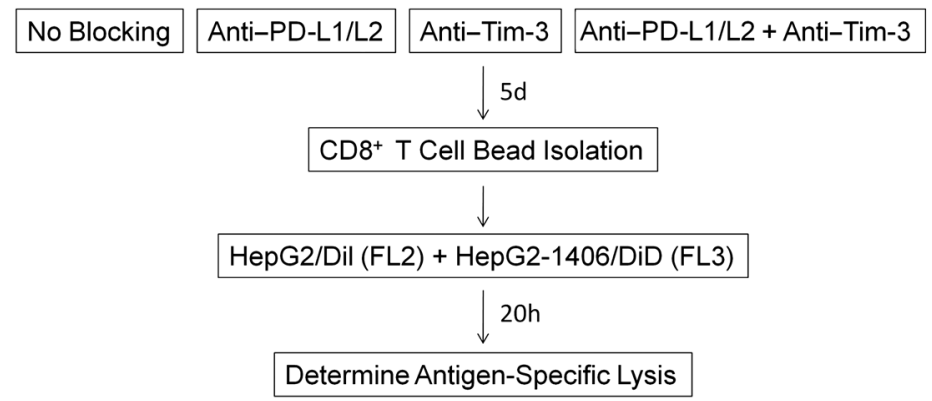

B

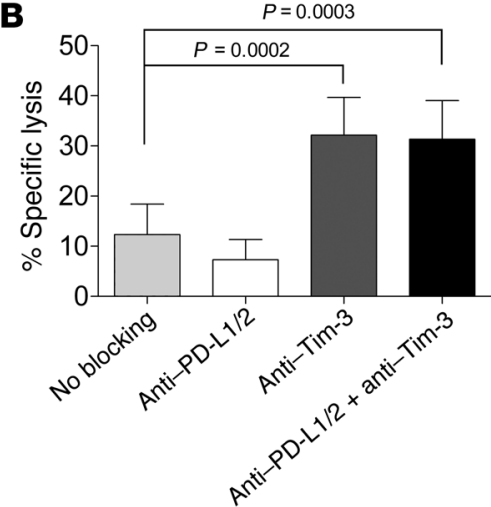

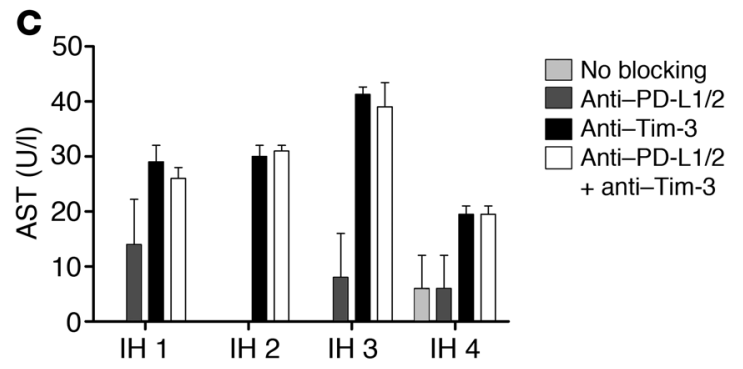

Figure 8

Tim-3 blockade enhances antigen-specific CTL killing of hepatocytes. (A) Experimental design to assess how Tim-3 and/or PD-1 blockade affects cytotoxicity of HCV-specific CTLs against a hepatocyte cell line expressing an NS3 epitope. Cytotoxicity of NS3 ${ }_{1406}$-Specific T cells against HepG2 cells transduced with a NS3 ${ }_{1406-1415}$ minigene was determined using a variation of the VITAL assay. (B) Intrahepatic lymphocytes were stimulated for 5 days with $\mathrm{NS}_{1406}$ peptide and the indicated blocking antibodies, followed by CD8 ${ }^{+} \mathrm{T}$ cell bead isolation. HCV-specific T cells were then cocultured with HepG2 cells expressing the $\mathrm{NS}_{1406}$ minigene at a 0.5:1 effector/target ratio. Percent specific lysis was calculated (see Methods). Values denote mean \pm SEM of 6 patients; $P$ values were determined using paired 2-tailed $t$ test. (C) AST levels in the supernatants from B demonstrated an increase in cultures containing the Tim-3-blocking antibody. Values denote mean \pm SEM of triplicate samples.

defense against this common infection is compelling, including the demonstration, first in chimpanzees (7) and then in humans (8-10), that mutational escape predates the development of persistence. One major criticism of the mutational escape hypothesis has been that, although it is a highly mutable RNA virus, HCV is unlikely to evade the multispecific CTL responses observed in some chronically infected individuals (5). Furthermore, HCV infection is characterized by virus-specific CTLs that exhibit phenotypic changes consistent with early stages of differentiation with functional impairment or anergy (13). Upregulation of inhibitory receptors on exhausted $\mathrm{T}$ cells is an important mechanism of $T$ cell dysfunction during chronic viral infections (13), and the repertoire of known negative regulators expressed on $\mathrm{T}$ lymphocytes has expanded considerably in the past few years.

Numerous groups have studied the role of PD-1, an ITIM-containing inhibitory receptor expressed on activated $\mathrm{T}$ cells that binds 2 known ligands (PD-L1 [B7-H1] and PD-L2 [B7-DC]; ref. $34)$, in mediating the $\mathrm{T}$ cell hyporesponsiveness in $\mathrm{HCV}$. These studies have found that PD-1 expression is significantly increased in chronic infection $(35,36)$, is further enriched in the hepatic compartment (35-38), and predicts lack of response to combination antiviral therapy (39). Whether PD-1 expression on HCV-specific CTLs predicts spontaneous virologic outcome in acute infection remains controversial, with one group demonstrating that PD-1 levels do not differ significantly between those who clear infection and those who do not in the acute or chronic phase of infection (40), but another showing that PD-1 expression inversely corre- lates with viral clearance independent of viral level (14). Regardless of the reason for these differences, it is notable that the overlap in PD-1 expression was considerable in the acute $\rightarrow$ resolved versus acute $\rightarrow$ chronic patient groups.

Our prior results indicate that Tim-3 expression may play an important pathogenic role in patients with longstanding chronic $\mathrm{HCV}$ infection (17), correlating with a dysfunctional and senescent phenotype (CD127 $\left.{ }^{\text {lo }} \mathrm{CD} 57^{\mathrm{hi}}\right)$. The first important finding of the current study was that acute $\mathrm{HCV}$ infection differentially affected the expression of Tim- 3 on bulk $\mathrm{CD}^{+}$and $\mathrm{CD} 8^{+} \mathrm{T}$ cells: subjects who cleared HCV did not demonstrate increased Tim-3 expression on $\mathrm{CD}^{+} \mathrm{T}$ cells, whereas, regardless of whether viral infection was spontaneously controlled or became persistent, $\mathrm{CD}^{+} \mathrm{T}$ cells demonstrated upregulated Tim-3 expression that did not normalize until late after spontaneous recovery. It is hypothesized that Tim-3-expressing CD4 ${ }^{+} \mathrm{T}$ cells may not provide the $\mathrm{T}$ cell help in the earliest stages of infection that determines whether CTL effectors develop into long-lived $\mathrm{T}_{\mathrm{EM}}$ cells, conferring immune protection. Provision of adequate $\mathrm{CD}^{+} \mathrm{T}$ cell help via production of cytokines (41) or by assisting professional antigen-presenting cells via CD40/CD40L-mediated activation $(42,43)$ is a prerequisite for the generation of effective CTL memory and development of protective immunity to $\mathrm{HCV}$. We found that Tim $-3^{+} \mathrm{CD} 4^{+}$ $\mathrm{T}$ cells had impaired secretion of IL-2 (Supplemental Figure 6) compared with their Tim-3- counterparts, supporting this hypothesis and potentially identifying a useful marker to predict viral persistence. As shown in Figure 3B, at all time points studied, patients 

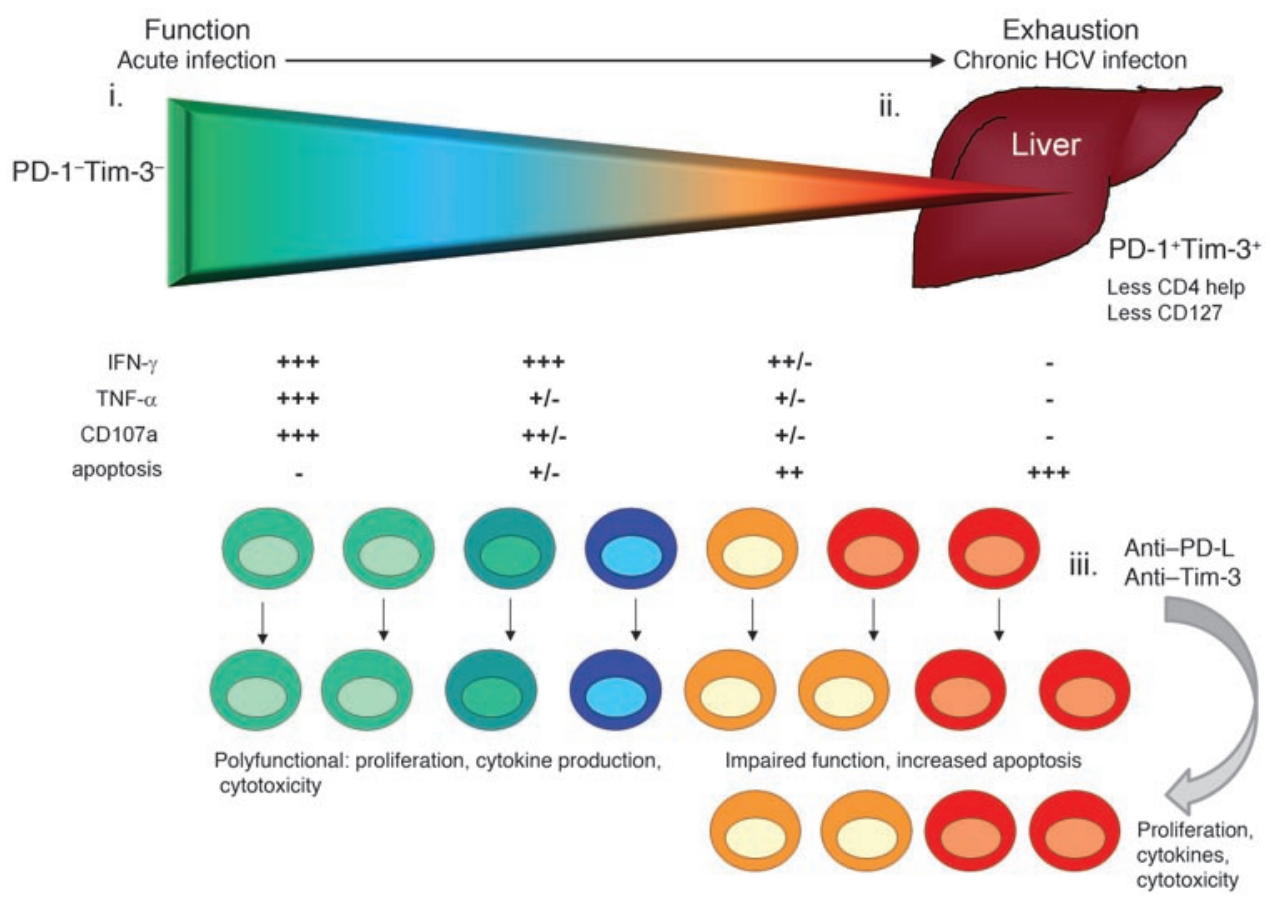

\section{Figure 9}

Gradient of function and exhaustion in HCV-specific T cells according to expression of Tim-3 and PD-1. PD-1-Tim-3- T cells (i) demonstrate a highly polyfunctional profile, with production of antiviral cytokines, cytotoxicity, and phenotype consistent with $\mathrm{T}_{\mathrm{EM}}$. Higher frequencies of these cells in acute HCV infection correspond to spontaneous viral eradication. At the other end of the spectrum, PD-1+Tim- $3^{+} \mathrm{T}$ cells (ii) accumulate in early HCV infection prior to development of persistence, demonstrate impaired CD4 help (decreased IL-2 production), impaired ability to secrete antiviral cytokines, and a phenotypic profile consistent with $\mathrm{T}_{\mathrm{CM}}$. Initially, TNF- $\alpha$ production is impaired, even though $\mathrm{CD} 8^{+} \mathrm{T}$ cells maintain the ability to produce IFN- $\gamma$ (ref. 13 and Figure 4B). The liver contains high expression of the ligands for PD-1 and Tim-3 (PD-L1/PD-L2 and galectin-9, respectively). The intrahepatic T cells express the highest level of PD-1+Tim- $3^{+}$T cells, consistent with the most exhausted phenotype, but dual blockade (iii) can restore function in many of these cells, including improved CD107a expression and attendant cytotoxicity.

who developed persistent $\mathrm{HCV}$ infection demonstrated higher frequencies of PD-1+Tim-3 $3^{+}$than PD-1-Tim-3- HCV-specific CTLs. Furthermore, $\mathrm{PD}-1^{+} \mathrm{Tim}-3^{+} \mathrm{CD} 8^{+} \mathrm{T}$ cells were predominantly of the $T_{\mathrm{CM}}$ phenotype, whereas $\mathrm{T}_{\mathrm{EM}}$ and EMRA cells were typically negative for coexpression.

Wherry and others $(20,44)$ have proposed a hierarchal model of CTL exhaustion that follows a pattern of progressive loss of function: decreased IL-2 and TNF- $\alpha$ secretion, followed by loss of IFN- $\gamma$ production. Exhaustion culminates in loss of all effector functions, including cytolytic activity, especially if epitope presentation to $\mathrm{T}$ cells is high as would be expected in the liver. Moreover, the ligands for PD-1 (PD-L1/PD-L2; ref. 37) and Tim-3 (galectin-9; ref. 45) are highly expressed in HCV-infected livers. The liver compartment contained the highest frequency of PD-1 ${ }^{\text {hi }}$ Tim- $3^{\text {hi }}$ HCV-specific CTLs and the lowest frequency of PD- $1^{\text {lo }}$ Tim- $3^{\text {lo }}$ CTLs (Figure 3D). Furthermore, our ex vivo data demonstrate that the extent to which Tim-3 and PD-1 are dually expressed on HCV-specific CTLs correlates with the spectrum of $\mathrm{T}$ cell functional impairment, persistence versus spontaneous eradication of viral infection, and the tissue microenvironment. Interestingly, a recent study in murine LCMV has demonstrated that dual expression of these inhibitory receptors is associated in vivo with development of chronic viral infection (28). Taken together, these results extend a paradigm in which increasing expression of PD-1 and Tim-3 correlates with progressive exhaustion of T cells (Figure 9).

Whether blockade of the PD-1 pathway leads mostly to a qualitative improvement in the polyfunctionality of CTLs or a quantitative increase in virus-specific CTLs by proliferative expansion remains open to question $(18,24)$. Recent work suggests that only a subset of exhausted CTLs can be functionally restored with PD-1/PD-L blockade (21), and our current results suggest a novel role for Tim-3 in demarcating particularly exhausted viral-specific PD- $1^{+}$ $\mathrm{T}$ cells. PD-1/PD-L1 blockade has been shown by others to enhance cytotoxicity only at the population level as a result of increased proliferation (46), but not at the single-cell level in exhausted cells (R. Ahmed, unpublished observation). In keeping with these results, we did not find that PD-1/PD-L1 blockade consistently enhanced cytotoxicity of HCV-specific CTLs, as assessed by $\mathrm{CD} 107$ a secretion or killing of HepG2 cells expressing cognate peptide. However, we demonstrated for the first time to our knowledge that significant cytotoxic activity was more frequently detected in $\mathrm{T}$ cell cultures (including intrahepatic CTLs) with anti-Tim-3 blockade, which sometimes worked additively with anti-PD-L blockade. The fact that Tim-3 blockade more consistently enhanced cytotoxicity of HCV-specific CTLs indicates that Tim-3 and PD- 1 are associated with distinct steps that mediate functional exhaustion in $\mathrm{T}$ cells. Work is ongoing to examine the transcriptional profile of $\mathrm{T}$ cells treated with anti-Tim-3 or anti-PD-L antibodies in order to define mechanistic differences.

In summary, our findings demonstrate that early accumulation of PD- $1^{+}$Tim- $-3^{+} \mathrm{T}$ cells is associated with functional impairment, and consequently with development of persistent HCV. The present study provides a basis for improving current therapies by simultaneous blockade of multiple inhibitory pathways that could result in additive efficacy without excessive toxicity (18).

\section{Methods}

Study population. The study protocol was approved by the Institutional Review Boards at Oregon Health Sciences University (Portland, Oregon, USA), University of Colorado Health Sciences Center (Denver, Colorado, USA), and 2 Alaska Native Tribal Health Corporations: ANTHC and South Central Foundation. All patients gave written consent for this study. The study population recruited for this study was composed of several groups of subjects (Table 1). This included Alaska Native/American Indian individ- 
uals identified from the ANTHC database who had never received antiviral therapy and were chronically infected $(n=20)$ or spontaneously resolved infection $(n=11)$. Genotype determination for subjects who were HCV RNA negative was performed at the French National Reference Center for viral hepatitis B, C, and delta (Créteil, France) using the HCV serotyping Murex 1-6 assay (Abbott Murex Diagnostics). This assay detects genotypespecific antibodies directed to epitopes encoded by the NS4 region of the $\mathrm{HCV}$ genome, but cannot discriminate among different subtypes of the same genotype (47). Because the assay is not available in the United States, results were provided by J.-M. Pawlotsky (Hôpital Henri Mondor, Créteil, France; ref. 23). All patients tested negative for HIV and HBV.

Sample preparation and storage. PBMCs were isolated from whole blood by Ficoll (Amersham Biosciences) density gradient centrifugation or cellular preparation tubes (anticoagulant sodium citrate; BD). PBMCs were viably frozen in 80\% FBS (BioWhittaker), 10\% DMSO, and 10\% RPMI 1640 Media (Life Technologies) in liquid nitrogen for subsequent analyses. Hepatic mononuclear cells (HMNCs) were isolated from explanted liver tissue at the time of liver transplantation for HCV-related liver disease. Tissue samples were dissected into $1-\mathrm{mm}^{3}$ pieces and added to RPMI 1640 medium and $0.05 \%$ collagen type IV $(312 \mathrm{U} / \mathrm{mg})$, and the mixture was incubated at $37^{\circ} \mathrm{C}$ for 60 minutes. The supernatant was removed, and cell pellets were diluted in RPMI 1640 medium and centrifuged at $125 \mathrm{~g}$ for 10 minutes. HMNCs were viably frozen in $80 \%$ FBS (as above) for subsequent analyses.

HCV epitope sequencing and viral load analysis. Plasma preparation tubes (PPT tubes; BD Biosciences) were used to isolate plasma from whole blood, which was frozen and later thawed for viral load and genotype testing. HCV genotyping (LiPA) and viral level determination (HCV RNA 3.0 bDNA; lower limit, 615 copies $/ \mathrm{ml}$ ) were performed by Siemens. For autologous virus sequencing, viral RNA was extracted from plasma samples using the vRNA extraction kit (Qiagen). A nested PCR with 12 external and 36 internal primer pairs spanning the entire $\mathrm{HCV}$ coding sequence amplified overlapping fragments of approximately $500-1.2 \mathrm{~kb}$, as previously described (48). PCR fragments were then purified (PCR Purification Kit; Qiagen) and population sequenced bidirectionally on an ABI 3730 PRISM automated sequencer (48).

Antibodies and flow cytometric analysis. Directly conjugated antibodies against the following surface molecules were used: CCR7-PE-Cy7 (clone 3D12), CD27-APC-H7 (clone M-T271), CD45RA-APC (clone HI100), CD69-FITC (clone L78), HLA-DR-PerCP (clone L243), CD45RO-PE-Cy7 (clone UCHL1), CD3-Pacific Blue (clone UCHT1), CD4-V500 (clone RPAT4), CD8-Alexa Fluor 700 or CD8-PerCP (clone SK1), and PD-1-FITC (clone MIH4), all from BD Biosciences; Tim-3 (clone 0323), from R\&D. The following intracellular antibodies were used: IL-2-APC (clone MQ1-17H12), from BD Biosciences. IFN- $\gamma$-Pacific Blue (clone 45.B3) and TNF- $\alpha$-Pacific Blue (clone Mab11) were from eBioscience, and CD107a (LAMP-1)-PerCPCy5.5 (clone H4A3) was from BioLegend.

Multiparameter flow cytometry was performed using a BD FACSCanto instrument (BD Biosciences) compensated with single fluorochromes and analyzed using FacsDiva software (BD Biosciences). Cryopreserved PBMCs and intrahepatic lymphocytes were analyzed for cell surface antigen expression following staining with antibodies at $4^{\circ} \mathrm{C}$ in the dark for 30 minutes. Cells were washed 3 times in $2 \mathrm{ml}$ PBS containing 1\% bovine serum albumin and $0.01 \%$ sodium azide and subsequently fixed in $200 \mu \mathrm{l}$ of $1 \%$ paraformaldehyde (Sigma-Aldrich). Dead cells were omitted by side scatter/forward scatter (SSC/ FSC) gating, and isotype-matched control antibodies were used to determine background levels of staining. Patients were assessed for antigen-specific CD8 ${ }^{+}$ T cell responses to HCV by HLA pentamer staining. PE- or allophycocyaninlabeled Pro5 pentamers were supplied by ProImmune (Supplemental Table 1). The A2-restricted CMVpp65 was used as a non-HCV control.

CFSE proliferation assay. PBMCs were resuspended at $1 \times 10^{7}$ cells $/ \mathrm{ml}$ PBS and stained with $0.63 \mu \mathrm{M}$ CFSE (Invitrogen) for 10 minutes at $37^{\circ} \mathrm{C}$. The reaction was stopped by resuspending in RPMI with $10 \%$ FBS. The cells were washed 3 times in PBS and then resuspended at $10 \times 10^{6} \mathrm{cells} / \mathrm{ml}$ in RPMI medium. CFSE-labeled cells were stimulated for 7 days with or without $\mathrm{HCV}$ peptide (final concentration, $10 \mu \mathrm{g} / \mathrm{ml}$ ) at $37^{\circ} \mathrm{C}$ and $5 \% \mathrm{CO}_{2}$. PD-L1/ PD-L2 blocking antibodies (eBioscience), Tim-3 blocking antibody (R\&D Systems), or control IgG antibodies (eBioscience) were added at $10 \mu \mathrm{g} / \mathrm{ml}$. Recombinant human IL-2 $(0.05 \mu \mathrm{g} / \mathrm{ml}$; NIH AIDS Research and Reference Reagent Program) was added on days 0 and 3. On day 7, cells were stained with HCV tetramer(s) and surface antigens as described above.

Intracellular cytokine staining and CD107 degranulation assay. PBMCs and intrahepatic lymphocytes were resuspended at $10 \times 10^{6} \mathrm{cells} / \mathrm{ml}$ in RPMI medium and stimulated for 7 days with or without $\mathrm{HCV}$ peptide (final concentration, $10 \mu \mathrm{g} / \mathrm{ml}$ ) at $37^{\circ} \mathrm{C}$ and $5 \% \mathrm{CO}_{2}$. PD-L1/PD-L2 blocking antibodies, Tim-3 blocking antibody, or control IgG antibodies were added at $10 \mu \mathrm{g} / \mathrm{ml} .10 \mu \mathrm{g} /$ $\mathrm{ml}$ peptide, CD107a antibody, and brefeldin A (Sigma-Aldrich) were added to the culture 5 hours prior to harvest according to the manufacturer's protocol. Cells were then washed twice, and cell surface staining for $\mathrm{HCV}$ pentamer, CD3, CD8, PD-1, and Tim-3 was performed. Intracellular cytokine staining for TNF- $\alpha$ and IFN- $\gamma$ was carried out using Caltag fixation and permeabilization solutions A and B according to the manufacturer's instructions (Caltag).

Hepatocyte cytotoxicity assays. A variation of the previously described VITAL killing assay was performed to determine $\mathrm{T}$ cell cytotoxicity against hepatocytes (33); FACS-based cytolysis assays have been demonstrated to yield high concordance with ${ }^{51} \mathrm{Cr}$-release assays (49). For the cytotoxicity assay, intrahepatic lymphocytes were stimulated with $10 \mu \mathrm{g} / \mathrm{ml} \mathrm{NS}_{1406}$ peptide in the presence of $10 \mu \mathrm{g} / \mathrm{ml}$ of the blocking antibodies anti-PD-L1, anti-PD-L2, and anti-Tim-3 for 5 days followed by $\mathrm{CD}^{+} \mathrm{T}$ cell magnetic bead isolation prior to coculture with the HepG2 cells. Target HepG2 cells expressing a NS3 ${ }_{1406}$ minigene or nontransduced HepG2 cells were labeled with the membrane dyes DiD and DiI according to the manufacturer's instructions (Invitrogen). The labeled target cells were then incubated in 96-well round-bottomed plates with magnetic bead-isolated $\mathrm{CD}^{+} \mathrm{T}$ cells (Miltenyi Biotec) at a 0.5:1 effector/target ratio based on the levels of staining with $\mathrm{NS}_{1406}$ pentamer. Antigen-specific lysis was calculated as previously described (33). AST was measured in the supernatants using a coupled enzymatic assay performed on a DXC 800 analyzer (Beckman-Coulter).

Statistics. Results are expressed as medians for nonparametrically distributed variables. The 2-tailed Wilcoxon rank-sum was used to compare differences between patient groups. 2-tailed Wilcoxon matched pairs signedrank tests were used in determining effects of blocking antibodies on cell cultures compared with cultures without the antibodies. A $P$ value less than 0.05 was considered significant. The Prizm 5.0 statistical analysis software was used (GraphPad Software) and confirmed by JMP 8 (SAS).

\section{Acknowledgments}

This research is supported by NIH grants RO1 DK060590 and U19 A 1066328 (HCV center grant) and VA Merit Review to H.R. Rosen, and by NIH grant RO1 AI 066209 to D.R. Gretch. We are grateful to the patients for their participation in the study, Steve Livingston and Lisa Townsend for helping coordinate specimen collection in Alaska, and Megan Brocato for specimen processing.

Received for publication March 26, 2010, and accepted in revised form September 22, 2010.

Address correspondence to: Hugo R. Rosen, University of Colorado Denver, GI \& Hepatology Division, B-158, Academic Office Building 1, 12631 East 17th Avenue, Room 7614, PO Box 6511, Aurora, Colorado 80045, USA. Phone: 303.724.1858; Fax: 303.724.1891; E-mail: Hugo.Rosen@ucdenver.edu. 
1. Weiss RA, McMichael AJ. Social and environmental risk factors in the emergence of infectious diseases. Nat Med. 2004;10(12 suppl):S70-S76.

2. Wang CC, et al. Acute hepatitis $\mathrm{C}$ in a contemporary US cohort: modes of acquisition and factors influencing viral clearance. J Infect Dis. 2007; 196(10):1474-1482.

3. Fried MW, et al. Peginterferon alfa-2a plus ribavirin for chronic hepatitis C virus infection. NEnglJ Med. 2002;347(13):975-982.

4. Lok AS, et al. Incidence of hepatocellular carcino$\mathrm{ma}$ and associated risk factors in hepatitis C-related advanced liver disease. Gastroenterology. 2009; 136(1):138-148.

5. Bowen DG, Walker CM. Adaptive immune responses in acute and chronic hepatitis $C$ virus infection. Nature. 2005;436(7053):946-952.

6. Fuller MJ, et al. Selection-driven immune escape is not a significant factor in the failure of CD4 T cell responses in persistent hepatitis $\mathrm{C}$ virus infection. Hepatology. 2010;51(2):378-387.

7. Kimura Y, Gushima T, Rawale S, Kaumaya P, Walker CM. Escape mutations alter proteasome processing of major histocompatibility complex class I-restricted epitopes in persistent hepatitis $C$ virus infection. J Virol. 2005;79(8):4870-4876.

8 . Tester I, et al. Immune evasion versus recovery after acute hepatitis $\mathrm{C}$ virus infection from a shared source. J Exp Med. 2005;201(11):1725-1731.

9. Cox AL, et al. Cellular immune selection with hepatitis C virus persistence in humans. J Exp Med. 2005. 201(11):1741-1752.

10. Bowen DG, Walker CM. Mutational escape from CD8+ T cell immunity: HCV evolution, from chimpanzees to man. J Exp Med. 2005;201(11):1709-1714.

11. Ha SJ, West EE, Araki K, Smith KA, Ahmed R. Manipulating both the inhibitory and stimulatory immune system towards the success of therapeutic vaccination against chronic viral infections. Immunol Rev. 2008;223:317-333.

12. Wherry EJ, et al. Molecular signature of CD8+ $\mathrm{T}$ cell exhaustion during chronic viral infection. Immunity. 2007;27(4):670-684.

13. Virgin HW, Wherry EJ, Ahmed R. Redefining chronic viral infection. Cell. 2009;138(1):30-50.

14. Rutebemberwa A, et al. High-programmed death-1 levels on hepatitis $C$ virus-specific $T$ cells during acute infection are associated with viral persistence and require preservation of cognate antigen during chronic infection. J Immunol. 2008;181(12):8215-8225.

15. Monney L, et al. Th1-specific cell surface protein Tim-3 regulates macrophage activation and severity of an autoimmune disease. Nature. 2002; 415(6871):536-541.

16. Jones RB, et al. Tim-3 expression defines a novel population of dysfunctional $\mathrm{T}$ cells with highly elevated frequencies in progressive HIV-1 infection. J Exp Med. 2008;205(12):2763-2779.

17. Golden-Mason L, et al. Negative immune regulator Tim-3 is overexpressed on T cells in hepatitis C virus infection and its blockade rescues dysfunctional CD4+ and CD8+ T cells. J Virol. 2009; 83(18):9122-9130.

18. Kaufmann DE, Walker BD. PD-1 and CTLA-4 inhibitory cosignaling pathways in HIV infection and the potential for therapeutic intervention. J Immunol. 2009;182(10):5891-5897.

19. Radziewicz $H$, et al. Impaired hepatitis $C$ virus (HCV)-specific effector CD8+ T cells undergo massive apoptosis in the peripheral blood during acute $\mathrm{HCV}$ infection and in the liver during the chronic phase of infection. J Virol. 2008;82(20):9808-9822.

20. Blattman JN, Greenberg PD. PD-1 blockade: rescue from a near-death experience. Nat Immunol. 2006;7(3):227-228

21. Blackburn SD, Shin H, Freeman GJ, Wherry EJ. Selective expansion of a subset of exhausted CD8 T cells by alphaPD-L1 blockade. Proc Natl Acad Sci US A. 2008;105(39):15016-15021.

22. Betts MR, et al. HIV nonprogressors preferentially maintain highly functional HIV-specific CD8+ T cells. Blood. 2006;107(12):4781-4789.

23. Smyk-Pearson $S$, et al. Spontaneous recovery in acute human hepatitis $\mathrm{C}$ virus infection: functional T-cell thresholds and relative importance of CD4 help. J Virol. 2008;82(4):1827-1837.

24. Blackburn SD, Crawford A, Shin H, Polley A, Freeman GJ, Wherry EJ. Tissue-specific differences in PD-1 and PD-L1 expression during chronic viral infection: implications for CD8 T-cell exhaustion. J Virol. 2010;84(4):2078-2089.

25. Burgers WA, et al. Association of HIV-specific and total CD8+ T memory phenotypes in subtype C HIV-1 infection with viral set point. JImmunol. 2009 182(8):4751-4761.

26. Saule P, Trauet J, Dutriez V, Lekeux V, Dessaint JP, Labalette M. Accumulation of memory T cells from childhood to old age: central and effector memory cells in CD4(+) versus effector memory and terminally differentiated memory cells in CD8 $(+)$ compartment. Mech Ageing Dev. 2006;127(3):274-281.

27. Derre L, et al. BTLA mediates inhibition of human tumor-specific CD8 $+\mathrm{T}$ cells that can be partially reversed by vaccination. J Clin Invest. 2010 ; 120(1):157-167.

28. Jin HT, et al. Cooperation of Tim-3 and PD-1 in CD8 T-cell exhaustion during chronic viral infection. Proc Natl Acad Sci U S A. 2010;107(33):14733-14738.

29. Sallusto F, Lenig D, Forster R, Lipp M, Lanzavecchia A. Two subsets of memory $T$ lymphocytes with distinct homing potentials and effector functions. Nature. 1999;401(6754):708-712.

30. Gruener NH, et al. Sustained dysfunction of antiviral CD8+ T lymphocytes after infection with hepatitis C virus. J Virol. 2001;75(12):5550-5558.

31. Wedemeyer $\mathrm{H}$, et al. Impaired effector function of hepatitis $\mathrm{C}$ virus-specific CD8+ $\mathrm{T}$ cells in chronic hepatitis C virus infection. J Immunol. 2002; 169(6):3447-3458.

32. Rosen HR, et al. Cutting edge: identification of hepatitis $\mathrm{C}$ virus-specific $\mathrm{CD} 8+\mathrm{T}$ cells restricted by donor HLA alleles following liver transplantation. J Immunol. 2004;173(9):5355-5359.

33. Hermans IF, et al. The VITAL assay: a versatile fluorometric technique for assessing CTL- and NKT-mediated cytotoxicity against multiple targets in vitro and in vivo. J Immunol Methods. 2004;285(1):25-40.

34. Chen L. Co-inhibitory molecules of the B7-CD28 family in the control of T-cell immunity. Nat Rev Immunol. 2004;4(5):336-347.

35. Radziewicz H, et al. Liver-infiltrating lymphocytes in chronic human hepatitis $\mathrm{C}$ virus infection display an exhausted phenotype with high levels of PD-1 and low levels of CD127 expression. J Virol. 2007; 81(6):2545-2553

36. Golden-Mason L, Palmer B, Klarquist J, Mengshol JA, Castelblanco N, Rosen HR. Upregulation of $\mathrm{PD}-1$ expression on circulating and intrahepatic hepatitis $\mathrm{C}$ virus-specific CD8+ T cells associated with reversible immune dysfunction. J Virol. 2007; 81(17):9249-9258.

37. Kassel R, Cruise MW, Iezzoni JC, Taylor NA, Pruett TL, Hahn YS. Chronically inflamed livers up-regulate expression of inhibitory B7 family members. Hepatology. 2009;50(5):1625-1637.

38. Nakamoto N, et al. Synergistic reversal of intrahepatic $\mathrm{HCV}$-specific CD8 T cell exhaustion by combined PD-1/CTLA-4 blockade. PLoS Pathog. 2009; 5(2):e1000313

39. Golden-Mason L, Klarquist J, Wahed AS, Rosen HR. Cutting edge: programmed death-1 expression is increased on immunocytes in chronic hepatitis C virus and predicts failure of response to antiviral therapy: race-dependent differences. Jimmunol. 2008; 180(6):3637-3641.

40. Kasprowicz V, et al. High level of PD-1 expression on hepatitis $\mathrm{C}$ virus (HCV)-specific CD8+ and CD4+ $\mathrm{T}$ cells during acute $\mathrm{HCV}$ infection, irrespective of clinical outcome. JVirol. 2008;82(6):3154-3160.

41. Kaech SM, Wherry EJ, Ahmed R. Effector and memory T-cell differentiation: implications for vaccine development. Nat Rev Immunol. 2002;2(4):251-262.

42. Lu Z, Yuan L, Zhou X, Sotomayor E, Levitsky HI, Pardoll DM. CD40-independent pathways of T cell help for priming of CD8(+) cytotoxic T lymphocytes. J Exp Med. 2000;191(3):541-550.

43. Bennett SR, Carbone FR, Karamalis F, Flavell RA, Miller JF, Heath WR. Help for cytotoxic-T-cell responses is mediated by CD40 signalling. Nature. 1998;393(6684):478-480.

44. Wherry EJ, Blattman JN, Murali-Krishna K, van der Most R, Ahmed R. Viral persistence alters CD8 T-cell immunodominance and tissue distribution and results in distinct stages of functional impairment. J Virol. 2003;77(8):4911-4927.

45. Mengshol JA, et al. A crucial role for Kupffer cellderived galectin-9 in regulation of $\mathrm{T}$ cell immunity in hepatitis C infection. PLoS One. 2010;5(3):e9504.

46. Barber DL, et al. Restoring function in exhausted CD8 T cells during chronic viral infection. Nature. 2006;439(7077):682-687.

47. Pawlotsky JM, et al. Serological determination of hepatitis $\mathrm{C}$ virus genotype: comparison with a standardized genotyping assay. J Clin Microbiol. 1997; 35(7):1734-1739.

48. Kuntzen T, et al. Viral sequence evolution in acute hepatitis C virus infection. J Virol. 2007; 81(21):11658-11668.

49. Sheehy ME, McDermott AB, Furlan SN, Klenerman $\mathrm{P}$, Nixon DF. A novel technique for the fluorometric assessment of $\mathrm{T}$ lymphocyte antigen specific lysis. J Immunol Methods. 2001;249(1-2):99-110. 